\title{
Vertical Networks, Integration, and Connectivity
}

\section{Citation}

Dogan, Pinar. 2009. Vertical Networks, Integration, and Connectivity. Journal of Economics and Management Strategy 18(2): 347-392.

\section{Published Version}

http://onlinelibrary.wiley.com/doi/10.1111/j.1530-9134.2009.00217.x/abstract

\section{Permanent link}

http://nrs.harvard.edu/urn-3:HUL.InstRepos:4863169

\section{Terms of Use}

This article was downloaded from Harvard University's DASH repository, and is made available under the terms and conditions applicable to Other Posted Material, as set forth at http:// nrs.harvard.edu/urn-3:HUL.InstRepos:dash.current.terms-of-use\#LAA

\section{Share Your Story}

The Harvard community has made this article openly available.

Please share how this access benefits you. Submit a story.

\section{Accessibility}




\title{
Vertical Networks, Integration, and Connectivity*
}

\author{
Pınar DOĞAN \\ Harvard John F. Kennedy School of Government \\ Harvard University \\ 79 JFK Street, Cambridge, MA 02138 \\ pinar_dogan@ksg.harvard.edu
}

* I am greatly indebted to an anonymous coeditor of this journal for comments and suggestions that lead to significant improvements in this paper. I also thank Jacques Crémer, Patrick Rey, Dani Rodrik, and Yeon-Koo Che for their extremely useful suggestions on earlier versions of this paper. An earlier version of this paper was circulated as "Vertical Integration in the Internet Industry." 


\begin{abstract}
This paper studies competition in a network industry with a stylized two layered network structure, and examines: (i) price and connectivity incentives of the upstream netwoks, and (ii) incentives for vertical integration between an upstream network provider and a downstream firm. The main result of this paper is that vertical integration occurs only if the initial installed-base difference between the upstream networks is sufficiently small, and in that case, industry is configured with two vertically integrated networks, which yields highest incentives to invest in quality of interconnection. When the installed-base difference is sufficiently large, there is no integration in the industry, and neither of the firms have an incentive to invest in quality of interconnection. An industry configration in which only the large network integrates and excludes (or raises cost of) its downstream rival does not appear as an equilibrium outcome: in the presence of a large asymmetry between the networks, when quality of interconnection is a strategic variable, the large network can exercise a substantial market power without vertical integration. Therefore, a vertically separated industry structure does not necessarily yield pro-competitive outcomes.
\end{abstract}

Keywords: Vertical Integration, Interconnection, Network Externalities.

JEL Classification: L13; L22; L86. 


\section{Introduction}

In this paper, I consider an industry with a stylized two-layered network structure. Within a given geographical area, two horizontally differentiated downstream firms compete to supply connectivity to end-users. In the upstream market, two interconnected networks with asymmetric installed-bases compete to provide connectivity to downstream firms. The quality of interconnection between the upstream networks is inferior to the quality of connectivity within a given network (on-net connectivity), unless both networks undertake costly investments. I analyze competition in such an industry, focusing on the incentives for vertical integration and the implications for the equilibrium quality of interconnection between upstream networks. A key result is that vertical foreclosure-in which the large upstream firm integrates downwards and excludes (or raises the costs of) the other downstream firm-is never an equilibrium in this setting. Depending on the difference in installed bases upstream, either both firms integrate vertically or neither does.

I show that when the installed base difference between the networks is sufficiently small, the equilibrium industry configuration is characterized by two vertically integrated networks. This is true regardless of which network moves first to decide on integration, as vertical integration is the dominant strategy for both networks for small installed base differences. Two successive mergers not only yield the lowest prices among all industry configurations, but also the highest incentives to invest in quality of interconnection.

When the installed base difference between the networks is sufficiently large, the equilibrium industry configuration is characterized instead by vertical separation, and neither one of the networks invests in quality of interconnection. The reason is as follows. For a given degree of asymmetry in the installed bases, a lower quality of interconnection facilitates exercise of market power by the large network, which in turn has no incentives to invest in quality of interconnection. When the industry is vertically separated, for the range of connectivity prices such that both downstream firms obtain non-negative profits regardless of their network choice, choosing an upstream network for connectivity constitutes a coordination (sub)game. Both downstream firms get symmetric profits as long as they connect to the same upstream network, and they obtain the same profits regardless of which network they coordinate on. But the presence of an asymmetry in the installed bases makes connecting to the small network a risky strategy, which enables the large network to supply connectivity to both firms, and at a higher price than that set by the smaller network. When the 
quality of interconnection is poor, a larger installed base advantage translates to higher connectivity prices (that are ultimately passed on the end-users), and hence to higher profits for the large network. The result is that the large network ends up supplying both downstream firms. ${ }^{1}$ This is a similar result to those obtained in models of competing upstream firms with asymmetric costs. ${ }^{2}$

Finally, regardless of which network moves first, an industry configuration in which only the large network integrates and raises its downstream rival's cost (or forecloses it) does not emerge as an equilibrium outcome. An interesting feature here is that when the small network moves first and does not integrate, the large network does not integrate either, if the installed-base difference is sufficiently large. This is because vertical integration does not facilitate the large network's exercise of market power in this instance, and vertically separated industry yields higher industry profits than any other industry structure (at the expense of higher prices for end-consumers). Therefore if the asymmetry between the networks' installed-bases is large, a vertically separated industry structure does not necessarily yield pro-competitive outcomes.

This is a result that contrasts with the vertical foreclosure literature in which upstream firms provide a homogenous inputs to downstream. For example, in the successive duopoly considered by Ordover et al. (1990), where upstream firms compete a-la-Bertrand with homogenous products, vertical foreclosure followed by integration is an equilibrium outcome. Beard et al (2001) consider a successive duopoly setting in which one upstream sector is dominated by one firm. They show that the vertically integrated dominant firm may raise its downstream rival's cost by degrading its quality of input-what the authors call sabotage-in particular when the dominant firm's pricing decisions are constrained by regulation. ${ }^{3}$ In their seminal paper, Hart and Tirole (1990) provide analysis for three variant models. The setting in the present paper resembles the one authors name ex post monopolization and focus on incentives for a relatively efficient upstream firm to vertically integrate and restrict output in the downstream market. In contrast to my approach, these authors consider secret contract offers made to downstream firms, and show that with deterministic costs, two possible industry configurations are (i) vertical separation, and (ii) vertical integration that only involves the efficient upstream firm. In the latter, the integrated firm supplies its nonintegrated downstream rival, but restricts its supplies as much as possible. ${ }^{4}$ However, as the authors argue, when the offers are public, (ii) may not be an equilibrium outcome. For example, at the extreme, when one of the upstream firms has 
infinite marginal cost, the more efficient upstream firm has no incentive to merge with a downstream firm, as it can exercise full market power even without integration. ${ }^{5}$ One contribution of the present paper is to show that in the presence of network externalities, when quality of interconnection is a strategic variable, it does not take too large an asymmetry to obtain this result. We can obtain the result within the range of sufficiently small installed base differences that preclude market cornering.

The model presented in this paper is potentially relevant to industries with network externalities in which competing downstream firms choose their upstream network providers. Consider for example the competition among Mobile Virtual Network Operators (MVNOs) that do not own spectrum licenses and a network infrastructure and rely on licensed Mobile Network Operators' (MNO) networks to provide their mobile services. Access of MVNOs to MNOs' networks remains, by and large, unregulated ${ }^{6}$ in many countries, and MNOs tend to provide connectivity to MVNOs on a voluntary basis. One reason why MNOs provide access to MVNOs is that the latter target specific niche markets (rather than mass markets) which MNOs have not been able to reach and offer substantially differentiated services compared to those offered by the host MNO. For example, some MVNOs which target teenagers provide advance applications that enable multi-player games. ${ }^{7}$ Interconnection between MNOs is often subject to regulation, but the quality of interconnection is in general more difficult to verify and hence to regulate.

Another possible example is the Internet, where the interconnection structure is also hierarchical. Individuals and businesses sit at the bottom of the hierarchy, and connect their end-systems (PCs, workstations, etc.) to local Internet Service Providers (ISPs), which are in turn connected to the Internet Backbone Providers (or to regional ISPs) which are interconnected. The quality of the interconnection within the backbone layer is determined in part by the choices made by the Internet Backbone Providers. Earlier papers on connectivity in the Internet consider models where the quality of interconnection and the prices for end-users are decided by the same agent (Crémer et al. [2000], Foros and Hansen [2001], Malueg and Schwartz [2006]). In contrast to those analyses, this paper captures the multi-layered structure of the Internet. On the other hand, the more competitive the upstream sector, the less suitable becomes the framework of the present paper.

Finally, since the choice over the quality of interconnection is analogous to a choice over the degree of 
compatibility, ${ }^{8}$ the present analysis can apply more generally to vertical markets characterized by network externalities. The compatibility incentives of firms in the presence of network externalities has been studied extensively in the literature. However, the question has not been addressed in a vertical setting where compatibility decisions are made by upstream providers. ${ }^{9}$ For example, when individual users buy an Apple notebook, they have no choice but to use Macintosh as the operating system (OS). On the other hand, those that buy, for example, one of Sony's SZ series notebooks, have no choice but to use Windows Vista as the OS -although Microsoft and Sony are not vertically integrated. Therefore, end-users' decision of which computer

to buy is tied another decision: which OS to use. ${ }^{10}$ Due to significant network externalities, some of the important determinants of the end-user's decision on which notebook to buy include (i) computer manufacturers' (downstream) choice of OS provider (upstream), (ii) the installed-bases of competing operating systems, and (iii) the degree of compatibility between the operating systems. ${ }^{11}$

The organization of the paper is as follows. In Section 2, I present the model for a vertically separated industry, and solve for the equilibrium. In Section 3, I introduce an initial stage to the game, where the upstream networks sequentially decide whether or not to vertically integrate with one of the downstream firms. After characterizing the equilibrium price and quality of interconnection for each subgame, i.e., for each industry configuration, I analyze incentives for vertical integration. Following the presentation of the main results, I conclude with a discussion section.

\section{Vertically Separated Industry}

Upstream Networks In the stylized network structure represented in Figure 1, two upstream networks, $\mathrm{U}_{A}$ and $\mathrm{U}_{B}$, with installed-bases $\beta_{A}$ and $\beta_{B}$, respectively, provide connectivity to the downstream market. $\mathrm{U}_{A}$ has a larger installed-base, $\beta_{A}>\beta_{B} \geq 0 .{ }^{12}$

The quality of connectivity is denoted with $\theta$. All users within the same upstream network enjoy perfect connectivity $\left(\theta_{\text {in-net }}=1\right)$. Unless both networks undertake investments in quality, the quality of interconnection between networks is at a minimum, normalized to zero. Cost of investment in quality is defined as

$$
\varsigma\left(\theta_{\text {off-net }}\right)=\frac{\theta_{\text {off-net }}^{2}}{2}
$$


Since off-net connectivity is a strategic choice variable, whereas in-net connectivity is not, for expositional simplicity, I refer to $\theta_{\text {off-net }} \in[0,1]$ as $\theta \cdot{ }^{13}$

Finally, upstream networks have a symmetric cost of providing unit connectivity, which is also normalized to zero. They compete à-la Bertrand and charge $w_{A}$ and $w_{B}$, respectively, for unit connectivity to the downstream firms.

Downstream Firms In the downstream market, two firms, $\mathrm{D}_{1}$ and $\mathrm{D}_{2}$, purchase connectivity from one of the upstream networks and compete à-la Bertrand with differentiated services. They are located at the extremities of a segment of length 1 . I assume that $D_{1}$ is located at 0 , and $D_{2}$ at 1 .

\section{[Figure 1 here]}

End-users End-users are distributed uniformly with density 1 on the segment at whose extremities the downstream firms are situated. Each end-user has a unit demand for connectivity that is provided by the downstream firms. There are positive network externalities, and hence, an end-user's utility depends on the number of other users in the entire network. Parameter, $\delta$, with $\delta \in(0, \widehat{\delta})$ and $\widehat{\delta}<1$, captures the benefit of being connected to another customer. Since in-net connectivity is perfect, and since the quality of off-net connectivity is set by the upstream networks, the end-users' utility depends on both (i) their downstream provider's choice of the upstream network, and (ii) the rival provider's choice of the upstream network.

The end-user located at $x \in[0,1]$, who is connected to the network through the service provided by $\mathrm{D}_{i}$, which is in turn connected to the upstream network $\mathrm{U}_{n}$, with $n=A, B$, derives the following utility

$$
U_{i, n}=v-t\left|x-x_{i}\right|-p_{i}+ \begin{cases}\delta\left(\beta_{n}+q_{i}+\theta\left(\beta_{-n}+\left(1-q_{i}\right)\right)\right) & \text { if } \mathrm{D}_{-i} \text { connects to } \mathrm{U}_{-n} \\ \delta\left(\beta_{n}+q_{i}+\left(1-q_{i}\right)+\theta \beta_{-n}\right) & \text { if } \mathrm{D}_{-i} \text { connects to } \mathrm{U}_{n}\end{cases}
$$

where $x_{i}$ stands for the location of $\mathrm{D}_{i}, t$ is the standard transportation cost, $q_{i}$ and $\left(1-q_{i}\right)$ are the market shares of $\mathrm{D}_{i}$ and $\mathrm{D}_{-i}$, respectively, and $p_{i}$ is the connectivity price charged by $\mathrm{D}_{i}$. The fixed utility derived by connecting to any of the downstream firms, denoted by $v$, is assumed to be sufficiently large so that all end-users buy service from one of the two downstream firms. 
Let $\beta$ denote the installed-base difference between the upstream networks, i.e.,

$$
\beta=\beta_{A}-\beta_{B},
$$

and let

$$
\varphi \equiv \delta(1-\theta)<\widehat{\delta}
$$

We can interpret $\varphi \beta$ as the large upstream network's installed-base advantage. This is because for a given positive installed-base difference $(\beta>0)$, two upstream networks are perceived as completely identical from the end-users point of view if

i. the quality of interconnection between the upstream networks is the same as the quality of on-net connectivity $(\theta=1)$, and/or

ii. there are no network externalities $(\delta=0)$.

Either of the two conditions implies that the large network has no installed-base advantage in competition (i.e., $\varphi=0$ ). For any given level of imperfect connectivity, and positive network externalities, a greater magnitude of externalities and/or larger in installed-base differences imply a larger installed-base advantage. Finally, for any given positive $\delta$ and $\beta$, the installed-base advantage is higher when connectivity is lower, since a lower quality of connectivity increases the relative quality of service provided by the large upstream network, compared to that of the smaller one.

I assume that

$$
\beta<(t-\delta) / \delta
$$

This assumption limits the asymmetry in the size of the upstream networks, and assumes away "market cornering" 14 at the final market. It implies

$$
t>\delta \geq \varphi
$$

From now on, I normalize $t=1$ for expositional simplicity.

Timing of the Game The game consists of four stages. 
Stage 1 - Each upstream network noncooperatively decides on the quality of interconnection, $\theta_{n}$, and the effective quality of interconnection is determined by the lowest of these two qualities, that is $\theta=\min \left\{\theta_{A}, \theta_{B}\right\}$.

Stage 2 - The upstream networks set the prices of unit connectivity, $w_{A}$ and $w_{B}$.

Stage 3 - The downstream firms choose their upstream network provider.

Stage $4-$ The downstream firms set $p_{i}$, compete for the end-users, and profits are realized.

\section{The Equilibrium in the Vertically Separated Industry}

The main result of this subsection is Proposition 1, which shows that whenever the quality of interconnection between the upstream networks is imperfect, the risk dominant equilibrium is characterized by both downstream firms connecting to the large upstream network, and the large network obtaining a positive profit margin that amounts to its installed-based advantage. Proposition 2 shows that in the vertically separated industry, the equilibrium quality of interconnection between the upstream networks lies at the minimum. The latter result is basically an extension of the interconnection degradation result in Crémer et al. (2000) to a two-layered network structure. Before the formal proof, I present the intuition behind these results.

For all $\beta_{A}>\beta_{B}$, a higher quality of interconnection between the upstream networks is not only costly but also leads to more intense price competition. At the one extreme, when quality of interconnection is the same as the quality of in-net connectivity $(\theta=1)$ two networks are equivalent from the viewpoint of the end-users and competition drives prices to marginal cost. Therefore, by keeping the quality of off-net connectivity inferior to its on-net quality (i.e., by not investing in the quality of interconnection), the large upstream network preserves its quality advantage over the smaller network. When the quality of interconnection is inferior to on-net connectivity, connecting to the smaller network becomes a riskier strategy, which enables the large upstream network to supply connectivity to both downstream firms obtain a markup that reflects its installed-base advantage.

Let $w$ denote the difference between the unit price of connectivity charged by the upstream networks, i.e.,

$$
w=w_{A}-w_{B}
$$


Lemma 1 For all $w$ and $\theta<1$, in the pure strategy Nash equilibrium of the subgame the two downstream firms connect to the same upstream network.

Proof. Table 1 below summarizes the payoffs of the subgame where downstream firms choose their upstream network provider, with $h>1 / 2$ and $l=0$ for $w<\varphi \beta-3(1-\varphi)$, and $h=(3(1-\varphi)-w+\varphi \beta)^{2} / 18(1-\varphi)$ and $l=(3(1-\varphi)+w-\varphi \beta)^{2} / 18(1-\varphi)$ for $w \in[\varphi \beta-3(1-\varphi), 3(1-\varphi)+\varphi \beta]$, and $h=0$ and $l>1 / 2$ for $w>3(1-\varphi)+\varphi \beta$. The computation of the payoffs can be found in Appendix A.1.

\section{[Table 1 here]}

Let $\left(\mathrm{U}_{1}, \mathrm{U}_{2}\right)$ denote the strategy profile of the downstream firms, with the first and second terms describing $\mathrm{D}_{1}$ 's and $\mathrm{D}_{2}$ 's upstream network choice, respectively, with $1,2=A, B$.

The proof is straightforward for $w<\varphi \beta-3(1-\varphi)$ and $w>3(1-\varphi)+\varphi \beta$, for which $l$ and $h$ are zero respectively. The unique Nash equilibrium is $\left(\mathrm{U}_{A}, \mathrm{U}_{A}\right)$ for $w<\varphi \beta-3(1-\varphi)$ and is $\left(\mathrm{U}_{B}, \mathrm{U}_{B}\right)$ for $w>3(1-\varphi)+\varphi \beta$. For all $w \in[\varphi \beta-3(1-\varphi), 3(1-\varphi)+\varphi \beta]$ we have both $h$ and $l$ positive. The two downstream firms connect to different upstream networks, only if both $h$ and $l$ are greater than $1 / 2$. That is, if $3(1-\varphi)-w+\varphi \beta>3 \sqrt{(1-\varphi)}$ and if $3(1-\varphi)+w-\varphi \beta>3 \sqrt{(1-\varphi)}$. Adding two inequalities yield $6(1-\varphi)>6 \sqrt{(1-\varphi)}$, and by inequality (6) this implies, $\varphi^{2}>\varphi$, which in turn implies $\varphi>1$, establishing the contradiction. The two Nash equilibria are then $\left(\mathrm{U}_{A}, \mathrm{U}_{A}\right)$ and $\left(\mathrm{U}_{B}, \mathrm{U}_{B}\right)$.

Before I provide the intuition for Lemma 1, I briefly discuss the case in which the quality of interconnection between upstream networks is the same as the quality of on-net connectivity $(\theta=1)$. In such a case if the upstream networks charge the same price for connectivity, the downstream firms' choice of upstream network provider is irrelevant in terms of their potential market share, and hence their profits. This is because potential customers of each downstream firm would enjoy perfect connectivity in the entire network, regardless of their choice of downstream provider. Therefore, when $\theta=1$, there are four pure strategy Nash equilibria, $\left(\mathrm{U}_{A}, \mathrm{U}_{A}\right),\left(\mathrm{U}_{B}, \mathrm{U}_{B}\right),\left(\mathrm{U}_{A}, \mathrm{U}_{B}\right)$, and $\left(\mathrm{U}_{B}, \mathrm{U}_{A}\right)$; and the downstream firms share the market equally and obtain the same profits under all equilibria. If the upstream networks charge different prices, then the equilibrium is unique; both downstream firms get connected to the upstream network which sets a lower price for connectivity.

Lemma 1 shows that whenever the quality of interconnection is imperfect between the upstream networks 
$(\theta<1)$ downstream firms always connect to the same upstream network providers. When $w$ is sufficiently low, the dominant strategy for both downstream firms is to connect to $\mathrm{U}_{A}$. Likewise, when $w$ is sufficiently high, the dominant strategy for both downstream firms is to connect to $\mathrm{U}_{B}$. For intermediary values of $w$, for which downstream firms obtain non-negative profits regardless of their network choice, the situation displays a coordination game with two Nash equilibria, $\left(\mathrm{U}_{A}, \mathrm{U}_{A}\right)$ and $\left(\mathrm{U}_{B}, \mathrm{U}_{B}\right)$, in both of which the downstream firms connect to the to same upstream network.

When the downstream firms connect to the same upstream network, the end-users of both downstream firms enjoy the same quality of on-net connectivity and they pay the same price for the unit connectivity, and hence, firms end up sharing the local market equally. Since the unit cost of connectivity is entirely borne by the end-customers, both equilibria, $\left(\mathrm{U}_{A}, \mathrm{U}_{A}\right)$ and $\left(\mathrm{U}_{B}, \mathrm{U}_{B}\right)$, yield same and symmetric profits for the downstream firms regardless of $w$, and therefore, neither of the equilibrium payoff-dominates the other. If each firm connects to a different upstream network, whenever the quality of interconnection is inferior to the quality of on-net connectivity, the firm which is connected to the large upstream network has a competitive advantage with respect to its rival. For sufficiently low $w$, this makes connecting to the small network a riskier strategy.

I use the risk dominance of Harsanyi and Selten $(1988)^{15}$ as the equilibrium concept for this subgame in which firms choose their network providers, and with the following Lemma, I state the conditions for each of the two equilibria to constitute a risk dominant equilibrium.

Lemma 2 For all $\theta<1$, in the subgame where the downstream firms choose their upstream networks, $\left(U_{A}, U_{A}\right)$ is a risk dominant equilibrium if $w<\varphi \beta$, and $\left(U_{B}, U_{B}\right)$ is a risk dominant equilibrium if $w>\varphi \beta$.

Proof. By the definition of Harsanyi and Selten (1988), in this $2 \times 2$ symmetric game $\left(\mathrm{U}_{A}, \mathrm{U}_{A}\right)$ is a risk dominant equilibrium if and only if

$$
\frac{1}{2}\left(\frac{1}{2}\right)+\frac{1}{2} h>\frac{1}{2} l+\frac{1}{2}\left(\frac{1}{2}\right)
$$

which implies $h>l$. Given the assumption stated in (5), this inequality holds if and only if $w<\varphi \beta$. Similarly, one can show that $\left(\mathrm{U}_{B}, \mathrm{U}_{B}\right)$ is a risk dominant equilibrium if and only if $w>\varphi \beta$. 
Risk dominance provides a very intuitive prediction in this game. ${ }^{16}$ There are two pure strategy Nash equilibria, and the players cannot predict which equilibrium their opponent will lean towards, as both equilibria yield the same payoff. Assume that $1 / 2>h>l$. Then by choosing to connect to $\mathrm{U}_{B}$, a downstream firm takes the risk of getting payoff $l$, which is the smallest payoff in this game. However, by connecting to $\mathrm{U}_{A}$ it guarantees itself a payoff of at least $h$. Therefore, provided that $w<\varphi \beta$, i.e., $h>l$, connecting to $\mathrm{U}_{A}$ is less risky than connecting to $\mathrm{U}_{B}$ in this subgame. The reverse is true if $w>\varphi \beta$.

Proposition 1 In the second stage of the game $U_{A}$ sets $w_{A}=\varphi \beta$, and $U_{B}$ sets $w_{B}=0$, and both downstream firms connect to $U_{A}$.

Proof. It is straightforward from the gross profit functions of $\mathrm{U}_{A}$ and $\mathrm{U}_{B}$. We have

$$
\Pi_{A}=\left\{\begin{array}{ll}
w_{A} & \text { if } w<\varphi \beta \\
0 & \text { if } w>\varphi \beta
\end{array} \quad \text { and } \quad \Pi_{B}=\left\{\begin{array}{cc}
w_{B} & \text { if } w>\varphi \beta \\
0 & \text { if } w<\varphi \beta
\end{array}\right.\right.
$$

and Bertrand competition yields $w_{A}=\varphi \beta$ and $w_{B}=0$.

The installed-base advantage of the large upstream network is analogous to a cost advantage in price competition. The price of the small upstream network is driven to its marginal cost, whereas the large upstream network holds a markup which amounts to its installed-base advantage, and covers the market alone. $^{17}$

Proposition 2 In the vertically separated industry, the equilibrium quality of interconnection is at the minimum.

Proof. It follows from $\mathrm{U}_{A}$ 's optimization problem,

$$
\max _{\theta}\left\{\delta(1-\theta) \beta-\frac{\theta^{2}}{2}\right\}
$$

$\mathrm{U}_{B}$ has no incentives to invest in quality of interconnection either, since it obtains no profits in this market.

The equilibrium payoffs in the vertically separated industry are $\Pi_{A}=\delta \beta, \Pi_{B}=0$, and $\Pi_{1}=\Pi_{2}=1 / 2$. 


\section{Vertical Integration}

In this section I consider upstream networks deciding sequentially whether or not to integrate with one of the downstream firms. I first consider and present the case in which the large network moves first, and then I turn to the equilibrium where the small network moves first. Whenever integration occurs I assume that the integrated upstream network provides connectivity to its downstream subsidiary at marginal cost (zero). I do not consider the case where the integrated upstream network can commit to charge a positive price to its downstream subsidiary, as the internal price is not observable by the non-integrated downstream rival. ${ }^{18}$

Timing of the game: The game consists of six stages.

Stage $1-\mathrm{U}_{A}$ decides whether to integrate with one of the downstream firms (say $\mathrm{D}_{1}$ )

Stage 2 - Following $\mathrm{U}_{A}$ 's decision, $\mathrm{U}_{B}$ decides on integration. If integration does not occur at Stage 1, $\mathrm{U}_{B}$ decides whether to integrate with one of the downstream firms (say $\mathrm{D}_{2}$ ). If integration occurs at Stage $1, \mathrm{U}_{B}$ decides whether to engage in counter-merger (with $\mathrm{D}_{2}$ ).

Stages 3 to 6 - These stages of the game are similar to Stages 1-4 that are presented in Section 2.

I assume that upstream networks decide to integrate with one of the downstream firms only if profits under integration is larger than the sum of profits when there is no integration. Figure 2 depicts the extensive form of the game tree with some abuse of presentation (of stages 3,4 and 6 ).

In this setting, there are four industry configurations (subgames):

(1) vertical separation,

(2) the small upstream network is integrated with one of the downstream firms $\left(U_{B}-D_{2}\right)$,

(3) the large upstream network is integrated with one of the downstream firms $\left(\mathrm{U}_{A}-\mathrm{D}_{1}\right)$, and

(4) two integrated networks.

[Figure 2 here] 
Equilibrium prices, connectivity level and profits of subgame (1) are as in Section 2. For subgames (2) and (3), in which there is one integrated firm, possible outcomes regarding the non-integrated downstream firm's choice of upstream provider (in Stage 5) are denoted with (2a)-(2c) for subgame (2), and with (3a)-(3c) for subgame (3). For a given $w_{A}, w_{B}$ and $\theta$, gross payoffs of $\mathrm{D}_{1}, \mathrm{D}_{2}, \mathrm{U}_{A}$, and $\mathrm{U}_{B}$, that are realized after the competition for end-users are denoted with $\Pi_{1}^{i} \Pi_{2}^{i}, \Pi_{A}^{i}, \Pi_{B}^{i}$, respectively, for each industry configuration $i=(1),(2 \mathrm{a}), \ldots,(4)$. Computations of the payoffs for all subgames can be found in Appendix A.1-A.4 and are summarized in Appendix A.5.

\subsection{The Equilibrium}

Before I compute the equilibrium for subgames (2), (3), and (4), I rule out outcomes (2b) and (3b), in which the non-integrated downstream firm exits the market when only one of the upstream network is integrated, and I show that both integrated and non-integrated upstream networks are willing to supply connectivity to the non-integrated downstream firm in both subgames (2) and (3).

Lemma 3 In subgames (2) and (3), where one of the upstream network integrates with a downstream firm, there are no incentives for vertical foreclosure, and both upstream networks compete to provide connectivity to the non-integrated downstream firm.

Proof. See Appendix B.1.

In both subgames (2) and (3), the non-integrated upstream network has an incentive charge a nonnegative price and sell connectivity to the non-integrated downstream firm, as it would obtain no profits otherwise. In turn, the non-integrated downstream firm can obtain a non-negative market share when the price of connectivity is sufficiently low. Therefore, in both cases (2b) and (3b); if the integrated firm refuses to deal with the non-integrated downstream firm, or equivalently, charges too high a price to it, regardless of which upstream network is integrated the rival upstream network is better off by selling connectivity to the non-integrated downstream firm.

Note that this result hinges on assumption stated in inequality (5) that puts an upper bound on the installed-base difference and rules-out market cornering. For very large installed-base differences such that inequality (5) is violated, this may no longer be true as the non-integrated downstream firm may not be 
able to obtain a positive market share when it connects to the small upstream network unless the price of connectivity is negative (i.e., unless the small network subsidizes it). This, in turn, may give incentives to the large network to refuse to deal with the non-integrated downstream firm and to monopolize the downstream market.

Given that the non-integrated upstream firm is willing to provide the non-integrated downstream firm with connectivity, in both subgames (2) and (3), the integrated network also prefers to sell connectivity to its downstream rival, and this is true for all installed-base differences that satisfy the inequality (5). Again, if the installed-base difference is too high, this may no longer be true; in (2) the small integrated network may choose not to compete with the large upstream network for that it may require lowering the price of connectivity too much, and in (3) the large integrated network, which anticipates that its downstream rival will exit, may refuse to deal.

I proceed with characterizing the equilibrium price and the quality of interconnection for each subgame. Then, I move backwards and study incentives for vertical integration.

\section{Subgame (4): Two integrated networks}

Each vertically integrated upstream network provides connectivity to its own subsidiary at zero price, and hence, double-marginalization is completely mitigated in this industry configuration. For a given level of quality of interconnection, the gross profits are computed in Appendix A.4 and can be found below.

$$
\begin{aligned}
\Pi_{A}^{(4)}+\Pi_{1}^{(4)} & =\frac{(3(1-\varphi)+\varphi \beta)^{2}}{18(1-\varphi)} \\
\Pi_{B}^{(4)}+\Pi_{2}^{(4)} & =\frac{(3(1-\varphi)-\varphi \beta)^{2}}{18(1-\varphi)} .
\end{aligned}
$$

When there are two integrated networks in the industry, the only source of profits is the provision of service to the end-users. Both downstream firms obtain positive markets shares, and hence positive profits, for any quality of interconnection. For any given $\theta<1$, the integrated large network charges a higher price to end-users $\left(p_{1}^{(4)}>p_{2}^{(4)}\right)$ and obtains both a higher market share and higher profit than the integrated small network. The integrated large (small) upstream network's price, market share, and profits are (increasing) 
decreasing with the installed-base difference.

For any $\theta<1$, this industry configuration yields lower prices to end-consumers and a lower industry profits compared to the vertically separated industry; in which the large network exercises market power in the downstream sector.

Quality of Interconnection Lemma 4 characterizes the equilibrium quality of interconnection in this subgame.

Lemma 4 In subgame (4) the equilibrium quality of interconnection

(i) is determined by the large upstream network,

(ii) is decreasing with the size of the installed-base difference,

(iii) is positive for all $\beta \leq \widetilde{\beta}$ with

$$
\widetilde{\beta}=\frac{3(1-\delta)}{2-\delta}
$$

and is zero otherwise.

Proof. See Appendix B.2.

In this industry configuration the equilibrium connectivity is determined by the preference of the large upstream network. Gross profits of the small integrated network is increasing with $\theta$, whereas this is true for the large network only for small installed-base differences. This is because while a high quality of interconnectivity increases end-users' willingness to pay for access to both of the networks, at the same time it makes the large upstream network's quality of service less differentiated from that of the small network's. Besides the investment in the quality of connectivity, this constitutes an additional cost to the large network. While this cost is insignificant for small installed-base differences, for which the networks are already less differentiated (albeit at a poor quality of interconnection), it becomes significant with larger asymmetries. Therefore, even in the absence of cost of investment, the large network does not invest in quality of interconnection when the installed-base difference is sufficiently large.

Note that the treshold of installed-base difference, $\widetilde{\beta}$, above which the large network's gross profits are decreasing with connectivity is decreasing with the degree of network externalities. In the presence of a high 
degree of network externality, the large network prefers not to invest in quality of interconnection even if the asymmetry in the installed bases is small, as in the absence of a high quality of interconnection, network externalities further elevate the large network's competitive advantage.

In this industry configuration the connectivity incentives would be the highest if the networks had symmetric installed bases, in which case the equilibrium connectivity would be $\delta / 2$. Due to the cost of investment in quality, the equilibrium quality of interconnection would be still inferior to the quality of on-net connectivity. However, a larger network externality would give higher incentives to the symmetric networks to invest in it.

\section{Subgame (3): $\mathbf{U}_{A}-\mathbf{D}_{1}$ integration}

In this subgame, where the large upstream network is integrated with one of the downstream firms and the small upstream network is not, the non-integrated downstream firm, $\mathrm{D}_{2}$, chooses its upstream network provider. With Lemma 5 , I show that $\mathrm{D}_{2}$ buys connectivity from the large upstream network, and finally, with Lemma 6, I characterize the equilibrium quality of interconnection.

Lemma 5 In subgame (3), for any given $\theta<1$, the non-integrated downstream firm buys connectivity from the integrated network.

Proof. See Appendix B.3.

The equilibrium price at which the large upstream network sells connectivity to the non-integrated downstream firm,

$$
w_{A}^{(3)}=3-(3(1-\varphi)-\varphi \beta) / \sqrt{1-\varphi}
$$

is increasing, and hence its profits are decreasing, with the installed-base difference. Although both downstream firms' end-users experience the same in-net quality of connection, the non-integrated downstream firm has a disadvantage in downstream competition. The presence of network externalities enhances the large upstream network's ability to raise its downstream rival's cost. When there are positive network externalities, the integrated upstream network, even with no initial installed-base difference $(\beta=0)$ can charge a positive price, thanks to the potential customers of its subsidiary that adds to its installed-base. 
Note that for any $\theta<1$, we have $w_{A}^{(3)}>w_{A}^{(1)}=\varphi \beta$, which is true even in the absence of any initial installed-base difference. In contrast to a vertically separated industry, there is no coordination problem between the downstream firms (in choosing an upstream network). Potential customers of the integrated downstream firm further elevate the large upstream network's installed-base advantage, which makes the small upstream network even less attractive from the non-integrated downstream firm's point of view. This in turn, in the absence of perfect quality of interconnection, increases the ability of the large integrated network to charge a high connectivity price to the rival non-integrated downstream firm and raise its cost.

Quality of Interconnection In this industry configuration, neither of the networks has an incentive to invest in quality of interconnection. The small upstream network obtains no profits in this local market, and hence, has no incentive to invest in quality of interconnection. The large upstream network prefers minimum quality of interconnection, as its profits are increasing with the connectivity price it can charge to the non-integrated downstream firm (given that the latter obtains non-negative profits), and the maximum connectivity price it can charge to attract the non integrated firm is decreasing with the quality of interconnection.

Lemma 6 In subgame (3) none of the upstream networks has an incentive to invest in the quality of interconnection, and hence, the equilibrium quality of interconnection is at the minimum.

\section{Proof. See Appendix B.4.}

A high quality of interconnection reduces the competitive advantage of having a large installed-base, as the ability of the large network to charge a positive markup to the non-integrated network depends on how inferior the quality of interconnection is to the on-net quality of connectivity. By maintaining a poor quality of connectivity the large upstream network differentiates its quality of service from that of $\mathrm{U}_{B}$, and increases the non-integrated downstream firm's opportunity cost of buying connectivity from the small upstream network. This increases $w_{A}$, which in turn provides the subsidiary firm with a competitive advantage in downstream competition. ${ }^{19}$

The equilibrium quality of interconnection in subgame (3) is the same as in subgame (1), and it is strictly lower than that in subgame (4) for small installed-base differences, as the equilibrium quality of 
interconnection is positive in the latter.

\section{Subgame (2): $\mathrm{U}_{B}-\mathrm{D}_{2}$ integration}

In this subgame, where the small upstream network is integrated with one of the downstream firms, and the large upstream network is not, the non-integrated downstream firm, $\mathrm{D}_{1}$, chooses its upstream network provider. With the following Lemma I show that which upstream network sells access in equilibrium is determined by the size of the installed-base difference, and with Lemma 8, I characterize the equilibrium quality of interconnection.

It follows from Lemma 3 that in subgame (2), upstream networks compete for $\mathrm{D}_{1}$. Unlike subgame (3), which upstream network ends up selling connectivity in equilibrium depends on the size of the installedbase difference. This is because the small upstream network obtains additional installed-base through its subsidiary, and hence, for a sufficiently small initial installed-base differences it can have a competitive advantage in providing connectivity to the non-integrated downstream firm.

Lemma 7 In subgame (2), for any given $\theta<1$, the non-integrated downstream firm buys connectivity from the integrated upstream firm if $\beta \leq \widehat{\beta}$, with

$$
\widehat{\beta}=\frac{3 \sqrt{(1-\varphi)}-3(1-\varphi)}{\varphi}
$$

and from the non-integrated firm otherwise.

Proof. See Appendix B.5.

When the installed-base difference is sufficiently small the industry configuration is characterized by (2a), and by (2c) otherwise. For a given $\theta<1$, when the network externalities are significant, the integrated network can not attract the non-integrated downstream firm unless the asymmetry in the installed-base is sufficiently small. A higher degree of externality implies a lower treshold of installed base difference, $\widehat{\beta}$, below which the integrated network sells connectivity to the non-integrated firm. Furthermore, for a given level of externality, a higher quality of interconnection implies that the integrated network can attract the nonintegrated downstream firm in the presence of higher installed base disadvantage. However, when the 
installed-base difference between the upstream networks is sufficiently large, the small integrated upstream network can not attract the non-integrated downstream firm with a non-negative price.

Quality of Interconnection In this subgame, for all installed-base differences, the large network has no incentives to invest in quality of interconnection. Therefore, although the small network prefers a positive quality of interconnection, the quality of interconnection is at the minimum in the equilibrium.

Lemma 8 In subgame (2) the equilibrium quality of interconnection is at the minimum.

Proof. See Appendix B.6.

If $\beta \leq \widehat{\beta}$, the large upstream network makes no profits in this local market, and hence, has no incentives to invest in quality of interconnection. Therefore, when the integrated network provides connectivity to the entire local market, quality of interconnection between the upstream networks is at the minimum. The

large network has no incentives to invest in quality of connectivity if $\beta>\widehat{\beta}$ either. This is because when the installed base difference is sufficiently large, the non-integrated network buys connectivity from the large network. In such a case, the gross profit of the large network is decreasing with the quality of interconnection, since the price it can charge to the nonintegrated network decreases with the quality of interconnection. Therefore, regardless of $\beta$, the quality of interconnection in this subgame is at the minimum.

\subsection{Comparing Industry Configurations}

Before I study the incentives for vertical integration and characterize the equilibrium industry structure, I highlight the main differences in industry configurations (2), (3), and (4), which are depicted in Figure 3. As noted earlier, the upstream networks' choice of the non-integrated downstream firm in configuration (2) depends on the size of the installed-base difference; we have (2a) (i.e., $\mathrm{D}_{1}$ connects to $\mathrm{U}_{B}$ ) if $\beta \leq \widehat{\beta}$ and (2c) otherwise.

\section{[Figure 3 here]}

Quality of interconnection All industry configurations except for (4) yield the minimum quality of interconnection, zero. In the industry configuration (3) neither of the upstream networks has an incentive 
to invest in quality of interconnection; the small network does not obtain any profits in this market, and the large network's ability to raise its downstream rival's cost decreases with the quality of interconnection. In the industry configurations $(2 \mathrm{a})$ and $(2 \mathrm{~b})$ the large upstream network has no incentive to invest in quality of interconnection, but for different reasons. In (2a), the initial installed base difference is sufficiently small $(\beta \leq \widehat{\beta})$ so that the non-integrated downstream firm buys connectivity from the small integrated network, and hence, the large upstream network obtains no profits. In (2c), the large upstream network has a sufficiently large installed-base advantage, and sells connectivity to the non-integrated downstream firm. It has no incentive to invest in quality of interconnection since a higher quality mitigates the large upstream network's competitive advantage, and lowers the price it can charge the non-integrated downstream firm. In (4) both upstream networks have an incentive to invest in quality of interconnection if the installed-base difference is sufficiently low $(\beta \leq \widetilde{\beta})$; the large network has no incentive to do so otherwise $(\beta>\widetilde{\beta})$.

Connectivity Prices When there are two integrated networks, the internal connectivity prices equal marginal cost, by assumption. We have

$$
w_{A}^{(2 \mathrm{c})}<w_{A}^{(1)}<w_{A}^{(3)}
$$

which implies that connectivity prices are highest in the industry configuration (3). The large network can exercise greater market power when the industry is vertically separated than when there is one vertical integration that involves the small upstream network, (2c). This is because, when the small upstream network integrates with one of the downstream firms, unlike in (1) there is no coordination problem between the downstream firms. This favors the small integrated firm, and restricts the ability of the large network to charge a high connectivity price to the non-integrated downstream firm. Finally, unless the installed-base difference is too small, we also have $w_{B}^{(2 \mathrm{a})}<w_{A}^{(1)}$. If the initial installed-base difference is too small, then the small integrated upstream network (with its downstream subsidiary's potential consumers added to its installed-base) is effectively not "small," and hence, the connectivity price it charges to the downstream firm rival can exceed $w_{A}^{(1)}$ (which is low due to the small installed-base difference). 
Prices for end-consumers For any installed-base difference, industry configuration (4) yields the lowest prices for end-consumers among all the configurations. ${ }^{20}$ When there is one integrated firm in the industry (configurations (2) and (3)), a large asymmetry in the installed-bases hurts the non-integrated downstream firm, regardless of which upstream firm is integrated. First, consider sufficiently small installed-base differences $(\beta \leq \widehat{\beta})$ such that $(2)$ is characterized by $(2 \mathrm{a})$. We have

$$
p_{2}^{(4)}<p_{1}^{(4)}<p_{2}^{(2 \mathrm{a})}<p_{1}^{(3)}<p_{1}^{(2 \mathrm{a})}<p_{2}^{(3)} .
$$

In both (2a) and (3) the non-integrated downstream firm ( $\mathrm{D}_{1}$ and $\mathrm{D}_{2}$ respectively) has a competitive disadvantage, which is decreasing with the installed-base difference in (2a) and increasing with it in (3). Now, consider larger installed-base differences $(\beta \leq \widehat{\beta})$ such that $(2)$ is characterized by $(2 \mathrm{c})$. Then, we have $p_{2}^{(2 \mathrm{c})}<p_{1}^{(2 \mathrm{c})}<p_{2}^{(3)}$, and both $p_{1}^{(2 \mathrm{c})}$ and $\left(p_{1}^{(2 \mathrm{c})}-p_{2}^{(2 \mathrm{c})}\right)$ are increasing with the installed-base difference.

Last but not least, we have $p_{1}^{(3)}>p_{1}^{(1)}$ only for very small values of $\beta$, This is because in (3) doublemarginalization is mitigated, and except for very small values of $\beta$ with which the large network has a very poor ability to exercise market power in (1), the price charged by the integrated downstream firm is lower than the prices in the vertically separated industry. We have $p_{2}^{(3)}>p_{2}^{(1)}$ unless $\beta$ is sufficiently high, which means that despite of the raising rival's cost strategy the large network adopts in (3), prices for end users in (1) are higher than that charged by the non-integrated rival in (3) when the installed-base difference is sufficiently large. This relates to the large network's higher ability to exercise market power in a vertically separated industry in the presence of larger asymmetries.

Industry Profits Industry profits in (1) are greater than in (4). Regardless of the possible outcomes in (2), (2a) and (2c) that depend on the size of the installed-base difference, industry yields higher profits in (2) than in (4).

Interestingly, industry profits in (3) are higher than those in (1) only if the installed-base difference is sufficiently small. This is also true for the vertical sum of profits (i.e., we have $\Pi_{A}^{(3)}+\Pi_{1}^{(3)}>\Pi_{A}^{(1)}+\Pi_{1}^{(1)}$ only if $\beta$ is sufficiently small), and as I show in the next subsection, this is why the industry configuration (3) does not appear in equilibrium. In what follows, in order to illuminate this point, I explain how downstream 
and upstream profits change in (1) and (3) with respect to $\beta$.

First, in (3), the integrated downstream firm's profits (as well as the industry profits) are increasing with $\beta$, whereas in (1) they are independent of $\beta$, furthermore, the former is greater than the latter for all $\beta$. Secondly, in (3) the large upstream network's connectivity revenues are higher than in (1) only if beta is sufficiently small. To see why, consider $\beta=0$. When there is no initial asymmetry in installedbases, regardless of the quality of interconnection, the upstream network cannot charge a positive price for connectivity in (1), whereas this is not true in (3). In (3), in the absence of a perfect connectivity, the vertically integrated upstream network can charge a positive price to the downstream rival, thanks to its downstream subsidiary's potential customers that create an installed-base advantage. Therefore, in the presence of small installed-base differences, (3) yields higher upstream profits than in (1) as the large network cannot exercise much market power in (1). However, when $\beta$ is sufficiently high, (1) yields higher upstream profits compared to (3). In both (1) and (3), the the connectivity prices are increasing with $\beta$, but unlike in (1), the large network obtains connectivity revenues only from the nonintegrated downstream firm in (3). Furthermore, in contrast to (1), a higher $\beta$ (which translates to a higher a connectivity price in both configurations) leads to a lower market share for the non-integrated rival, which in turn implies that upstream profits are increasing with $\beta$ at a decreasing rate. The first and the second point together imply that while the large upstream network benefits from integration in terms of higher downstream profits, when $\beta$ is large it is harmed in terms of lower upstream profits. When $\beta$ is sufficiently high, the latter effect dominates the latter, and hence, (1) yields a larger sum of vertical profits than (3). To put it differently, the large network does not need to integrate to exercise a higher market power when $\beta$ is sufficiently large. Note that this is true only if there are positive network externalities and if quality of interconnection is a strategic variable. If the quality of interconnection were not a strategic variable, and was same as the quality of on-net connectivity, (1) would not lead to a higher industry profits for any installed-base difference.

\subsection{Incentives for Vertical Integration}

In this subsection I show that regardless of which upstream network moves first to decide on integration, (4)

is the equilibrium industry configuration for all $\beta \leq \widehat{\beta}$. I begin by characterizing the equilibrium when the 
large upstream network moves first.

Proposition 3 When the large upstream network moves first, there are two integrated networks in the industry if $\beta \leq \widehat{\beta}$, and there is no integration otherwise.

\section{Proof. See Appendix B.7.}

When the large network moves first, and integrates, the best response of the small network is to respond by a counter-merger. This is because if it does not integrate it obtains a zero profit, and the non-integrated downstream firm obtains low profits as the integrated network raises its cost by setting a high connectivity price. Therefore, a vertical integration between the small network and the non-integrated downstream firm yields a higher profit than the sum of their profits when they remain separate.

When the large network moves first, and does not integrate, the best response of the small network depends on the size of the installed-base difference. The best response of the small network is to integrate with one of the downstream firms if $\beta \leq \widehat{\beta}$. This is because when $\beta \leq \widehat{\beta}$, subgame (2) is characterized by (2a) in which the non-integrated network buys connectivity from the small integrated network, and hence there is room for a profitable integration, as the sum of vertical profits is higher than those obtained in (1). However, when $\beta>\widehat{\beta}$, the small network can not engage in a profitable merger, as in this range of installed-base differences, subgame (2) is characterized by (2c). On one hand, both in (1) and (2c) small upstream network obtains a zero profit. On the other hand, downstream firms share the market equally, and obtain a profit of $1 / 2$ in (1), whereas the integrated small network's subsidiary competes against the rival downstream that is connected to the larger network in (2c). Therefore, given that there is no integration in the industry, the small network can not engage in a profitable merger if the installed-base difference is sufficiently high.

To summarize, when $\beta \leq \widehat{\beta}$, the dominant strategy of the small network is to integrate, and when $\beta>\widehat{\beta}$ it can engage in a profitable merger only if the large network is already integrated. Given the small network's best response described above, the large network integrates if $\beta \leq \widehat{\beta}$, and not otherwise. This is because, when $\beta \leq \widehat{\beta}$ if it does not integrate, it gets zero profits, and the non-integrated downstream firm which competes against the small integrated network's subsidiary, obtains a low profit compared to what it would obtain under (4). If $\beta>\widehat{\beta}$, and if the large network integrates, the industry configuration is (4) as the small 
network responds with counter-merger. On the contrary, if it does not integrate, the industry configuration is (1) since the small network can not engage in a profitable merger. Since the sum of the large network's and any of the downstream firm's profits is higher in (1) than that of the integrated large network's in (4), the large network does not integrate.

Therefore, when the large network moves first and decides for integration, there are two vertical mergers if $\beta \leq \widehat{\beta}$, and none otherwise. When there are two mergers, the equilibrium quality of connectivity is decreasing with $\beta$, and it is positive for all $\beta \leq \widetilde{\beta}$ and at a minimum for all $\beta \in(\widetilde{\beta}, \widehat{\beta}]$. In a vertically separated industry the quality of interconnection is at a minimum.

As I show below, when the small upstream network moves first, the equilibrium industry structure also consists of two vertically integrated firms for $\beta \leq \widehat{\beta}$ (as integration in this range of $\beta$ is the dominant strategy for the small network). The following Proposition characterizes the equilibrium industry configuration when the small network is the first-mover.

Proposition 4 When the small upstream network moves first, if $\beta \leq \widehat{\beta}$ there are two vertical mergers, if $\beta \in(\widehat{\beta}, \bar{\beta})$ there is only $U_{B}-D_{2}$ merger, and if $\beta \geq \bar{\beta}$ there is no integration in the industry.

Proof. See Appendix B.8.

When the small network moves first and integrates, the best response of the large network is to integrate if $\beta \leq \widehat{\beta}$, and not to integrate otherwise. The reasoning is similar to why the large network integrates for all $\beta \leq \widehat{\beta}$ when it moves first.

When the small network moves first and does not integrate, the large network integrates if $\beta<\bar{\beta}$, and not otherwise (where $\bar{\beta}>\widehat{\beta}$ ). This is because, as explained earlier, industry profits in (3) are higher than in (1) only for small installed-base differences. For larger installed-base differences, the large network can exercise a large market power without engaging in vertical integration.

First consider an installed-base difference such that $\beta<\bar{\beta}$. Since $\bar{\beta}>\widehat{\beta}$ the small network anticipates that the large network will integrate if it observes no integration, and it will not integrate if it observes one. The former configuration is (3), whereas the latter is (2c). In both cases there is no source of upstream profits for the small network. However, the non-integrated downstream firm's profits in (3) are strictly lower than are in (2c), and hence, there is room for a profitable merger. This implies that the small network 
vertically integrates whenever $\beta<\bar{\beta}$, and the large network responds with a counter merger only if $\beta \leq \widehat{\beta}$.

Now consider $\beta \geq \bar{\beta}$. Then, regardless of the small network's integration decision, the large upstream network does not integrate. As the small network can not engage in a profitable merger (given that there is no other merger) for $\beta>\widehat{\beta}$, it remains non-integrated. Therefore, for all $\beta \geq \bar{\beta}$ the equilibrium industry configuration is characterized by vertical separation.

An interesting result is that, not integrating is the dominant strategy for the large upstream network for all $\beta \geq \bar{\beta}$. While it is intuitive why this is true when the small network integrates, it is counter-intuitive when the small network does not integrate. This is because, as we discussed earlier, when the installed-base difference is sufficiently large, as the large upstream network can exercise considerable market power without integrating vertically. Higher profits obtained by the downstream subsidiary do not compensate the loss in connectivity revenues that is brought about vertical integration.

For all $\beta \geq \bar{\beta}$ (equilibrium is characterized by vertical separation regardless of which network moves first) prices for end consumers are higher than what one would obtain in the presence of a vertical merger that

involves the large network. For all $\beta \geq \widehat{\beta}$ (equilibrium is characterized by vertical separation if large network moves first) prices are higher than what one would observe from the downstream subsidiary of the large network, and depending on $\beta$, they can be lower (for $\beta$ low) or higher (for $\beta$ high) than the price that would be charged by the non-integrated downstream firm. This implies that in the presence of a large asymmetries, the vertically separate industry structure is not necessarily pro-competitive and may yield higher prices for end-consumers than what one would observe if the large network were integrated and raised its downstream rival's cost.

The most desirable industry structure for consumers is the one with two vertical mergers, which yield lowest prices for end-consumers, and higher incentives to invest in quality of interconnection (at least in the presence of small asymmetries). This outcome, however, appears in equilibrium when the industry performs relatively well regardless of its configuration, i.e., when the installed-base difference is sufficiently small.

\section{Concluding Remarks}

By way of conclusion, I now discuss informally some possible extensions to the framework. 
Endogenous installed-bases In this paper I have considered two upstream networks with given installedbases competing in a (new) local market. I assumed that the decisions in this local market, in particular on the quality of interconnection, does not affect initially installed customers. One way to interpret this is as installed-base customers being locked in with prior contracts and there being sufficiently high switching costs that would prevent them moving from one network to another. Another way to think about this is to interpret the investment decisions that are made for quality of interconnection as those concerning only the new market. That is, given the initial quality of connectivity (set in other markets), networks decide how much to invest in additional infrastructure that improves quality of interconnection in the market subject to study. Zero quality of interconnection, with this regard, does not necessarily mean that the networks are completely disconnected.

Now, instead, consider two upstream networks with no installed-bases that will compete in $n$ local markets. The present framework is not appropriate to study competition and incentives for quality of interconnection in a setting, in which firms compete in $n$ markets simultaneously. This is because, depending on expectations of downstream firm in each market there can be multiple equilibria. However, given the findings of this paper, one can make conjectures on a sequential-game setting. Assume that two upstream networks compete in $n=1,2, \ldots, N$ markets sequentially. Since there are no installed-bases prior to competition $(\beta=0)$ in the first market we can have either of the networks supplying connectivity downstream. As long as upstream firms make simultaneous and public offers, we have four pure strategy Nash equilibria, $\left(\mathrm{U}_{A}, \mathrm{U}_{A}\right),\left(\mathrm{U}_{B}, \mathrm{U}_{B}\right),\left(\mathrm{U}_{A}, \mathrm{U}_{B}\right)$, and $\left(\mathrm{U}_{B}, \mathrm{U}_{A}\right)$, and all yield the same payoff to the downstream firms regardless of the quality of interconnection. The equilibria $\left(\mathrm{U}_{A}, \mathrm{U}_{A}\right)$ and $\left(\mathrm{U}_{B}, \mathrm{U}_{B}\right)$ would create an asymmetry in competition in the next market in line, which will amount to the size of the first market. However, by vertically integrating, each upstream firm can guarantee itself an installed-base that amounts to half of the first market. Therefore, vertical integration would be a dominant strategy for both upstream firms. The equilibria $\left(\mathrm{U}_{A}, \mathrm{U}_{B}\right)$ and $\left(\mathrm{U}_{B}, \mathrm{U}_{A}\right)$ would leave firms indifferent in terms of integration decisions, and whether integrated or not, upstream firms would compete in the next market in line with symmetric installed-bases.

This assumes, of course, that the upstream firms are completely symmetric and can not subsidize downstream market to build up installed-bases in the initial markets. Any asymmetry introduced in initial markets 
(e.g., by sponsored installed-base), would lead to two successive mergers in the preceding market, unless the installed-base difference is exceeds $\widehat{\beta}$, in which case markets may sequentially tip towards the larger network, which would remain non-integrated.

Multiple upstream/downstream firms Consider $n$ networks upstream networks, with $\beta_{1}>\beta_{2} \geq \ldots \geq$ $\beta_{n}$, such that $\beta_{1}>\sum_{i \neq 1}^{n} \beta_{i}$. Let $\theta_{i j}=\theta_{j i}$ denote quality of interconnectivity between networks $i$ and $j$, with $i, j=1,2, . ., n$, and $i \neq j$. Furthermore, for simplicity, assume that $\theta_{i j}=1$ for all $i, j \neq 1$, so that large network's rival networks are perfectly interconnected. ${ }^{21}$ Also assume that there are $k \leq n$ symmetric downstream firms. Then, in a vertically separated industry there is a similar coordination game between $k$ downstream firms when they choose their upstream network, which is likely to yield the same outcome as in this paper studied in Section 1: that is, by not investing in $\theta_{1 i}$, with $i=2, \ldots, n, \mathrm{U}_{1}$ can exercise market power that would be proportional to $\left(\beta_{1}-\sum_{i \neq 1}^{n} \beta_{i}\right)$. However, the entire analysis for vertical integration would now be different, in particular if $k<n$ and if any of the downstream firm can integrate only with one of the upstream network. Even if the number of downstream firms is the same as the number of upstream networks, the findings of this paper would not hold, due to a potential free-riding problem in investments in interconnectivity. Consider the case for example for $k=n$, where there are $n$ vertically integrated networks (the industry configuration that is analogous to (4) in this paper). If $\theta_{i j}=1$ for all $i, j \neq 1$, then it is enough for one of the smaller network $i$ to invest in $\theta_{1 i}$ (provided that $\mathrm{U}_{1}$ is also willing to invest) to have a higher quality of interconnection among all $n$ networks. Unless there are enforceable contracts that allow for side-payments, under-investment in quality of interconnection can rise as an issue. Consider also the configuration that is analogous to (3), in which only the large network is integrated. Then, potential competition upstream would give incentives to the large network to supply unintegrated networks, but unless the connectivity among the smaller rival networks is perfect, it would increase the ability of the large network to increase non-integrated rivals' cost (and for $\theta_{i j}=1$, with $i, j \neq 1$ the findings of this paper for (3) would apply).

Now consider $\beta_{1} \geq \beta_{2} \geq \ldots \geq \beta_{n}$, but without any restrictions on how large the largest network is. Then, almost anything can happen. Any subgame of the larger game that determines the equilibrium industry configuration is likely to involve multiple equilibria, which makes it hard to make any predictions. 
Large asymmetries in installed-bases The assumption which rules-out market cornering (inequality (5)) is a crucial assumption for the analysis provided above. When it is violated, that is when the installedbase difference between the upstream networks is too large, than vertical foreclosure followed by vertical integration of the large network can be an equilibrium outcome. When the installed-base difference is too large, then, the small network may not be able to engage in a profitable counter-merger. Furthermore, it may not be able to make the non-integrated downstream firm a profitable offer for connectivity (and hence, there would be no potential competition upstream either) which may ultimately lead to vertical foreclosure. However, when the installed-base difference is substantially high, the large network could also generate monopoly profits in the vertically separated structure.

Costly quality degradation I have assumed that quality of interconnection between the networks is inferior to that of on-net connectivity, unless the networks undertake costly investments. One could also assume that the on-net and off-net quality of connectivity is identical, unless firms engage in strategic quality degradation. Assuming a costly quality degradation (e.g., regulatory costs) does not change the qualitative nature of the results. The equilibrium industry configuration is characterized by two vertical mergers if the installed-base difference is sufficiently small, and by vertical separation if otherwise. When the equilibrium is characterized by two vertical mergers, the quality of interconnection is perfect, and it yields the highest quality of interconnection among other configurations. Industry configuration (3) which is never an equilibrium outcome, yields strictly lower quality of interconnection than (4). In both (1) and (3), the equilibrium quality of interconnection is determined by the large network, and is decreasing with the size of the installed-base difference. Different than the present setting, the small network's preferences determines the quality of interconnection in (2) for sufficiently small installed-base differences (so that the configuration is characterized by (2a)). In such a case the large network that sells no connectivity, has no incentives to engage in costly degradation, whereas the small network may find it profitable to do so. However, (2) does not appear as an equilibrium configuration. 


\section{References}

[1] Beard, R. T., D. L. Kaserman and J. W. Mayo, 2001, "Regulation, Vertical Integration and Sabotage," Journal of Industrial Economics, 49, 319-333.

[2] Church, J. and N. Gandal, 2000, "Systems Competition, Vertical Merger, and Foreclosure," Journal of Economics \& Management Strategy, 9, 25-51.

[3] Church, J. and N. Gandal, 2006, "Platform Competition in Telecommunications," M. Cave, S. Majumdar, and I. Vogelsang, I., eds. Handbook of Telecommunications Economics, Vol.2, Amsterdam: North Holland, 117-153.

[4] Crémer, J., P. Rey, P. and J. Tirole, 2000, "Connectivity in the Commercial Internet," Journal of Industrial Economics, 48, pp. 433-472.

[5] Economides, N., 1996, "The Economics of Networks," International Journal of Industrial Organization, 14, 673-99.

[6] Economides, N. and S. C. Salop, 1992, "Competition and Integration among Complements, and Network Market structure," Journal of Industrial Economics, 40, 105-23.

[7] Economides, N. and L. J. White, 1994, "Networks and Compatibility: Implications for Antitrust," European Economic Review, 38, 651-62.

[8] Farrell, J. and P. Klemperer, 2004, "Coordination and Lock-In: Competition with Switching Costs and Network Effects," M.. Armstrong, and R. Porter, eds. Handbook of Industrial Organization, Vol.3, Amsterdam: North Holland, 1967-2074.

[9] Farrell, J. and G. Saloner, 1992, "Converters, Compatibility, and the Control of Interfaces," Journal of Industrial Economics, 40, 9-35.

[10] Farrell, J. and G. Saloner, 1986, "Installed Base and Compatibility: Innovation, Product Preannouncements, and Predation," American Economic Review, 76, 940-55.

[11] Foros, Ø. and B. Hansen, 2001, "Competition and Compatibility among Internet Service Providers," Information Economics and Policy, 13, 411-425. 
[12] Harsanyi, J. C. and R. Selten, 1988, A General Theory of Equilibrium Selection on Games, Cambridge, MA: The MIT Press.

[13] Hart, O. and J. Tirole, 1990, "Vertical Integration and Market Foreclosure," Brookings Papers on Economic Activity: Microeconomics, 205-286.

[14] Katz, M. and C. Shapiro, 1985, "Network Externalities, Competition and Compatibility," American Economic Review, 75, 424-440.

[15] Kretschmer, T., 2004, "Upgrading and niche usage of PC operating systems," International Journal of Industrial Organization, 22, 1155-1182.

[16] Liebowitz, S. J. and S. Margolis, 2002, "Network Effects," M. Cave, S. Majumdar, and I. Vogelsang, I., eds. Handbook of Telecommunications Economics, Vol.1, Amsterdam: North Holland, 75-96.

[17] Malueg, D. A. and M. Schwartz, 2006, "Compatibility Incentives of a Large Network Facing Multiple Rivals," Journal of Industrial Economics, 54, 527-567.

[18] Mathewson, F. G. and R. A. Winter, 1987, "The Competitive Effects of Vertical Agreements: Comment," American Economic Review, 77, 1057-62.

[19] Ordover, J. A., G. Saloner and S. C. Salop, 1990, "Equilibrium Vertical Foreclosure," American Economic Review, 80, 127-142.

[20] Riordan, M. H., 2005, "Competitive Effects of Vertical Integration," P. Buccirossi, ed. Handbook of Antitrust Economics, Cambridge, MA: MIT Press, 145-182.

[21] Riordan, M. H., 1998, "Anticompetitive Vertical Integration by a Dominant Firm," American Economic Review, 88, 1232-1248.

[22] Rey, P. and J. Tirole, 2007, "A Primer on Foreclosure," M. Armstrong M. and R. Porter, eds. Handbook of Industrial Organization, Vol. 3, Amsterdam: North Holland, 2145-2220.

[23] White, L., 2007, "Foreclosure with Incomplete Information," Journal of Economics 83 Management Strategy, 16, 507-535. 


\section{Notes}

${ }^{1}$ In the presence of network externalities, a similar coordination problem raises also in the absence of an intermediary layer in competition, where end-users decide which network to join in. See for example, Church and Gandal (2006) for platform competition in telecommunications; end-users may be reluctant to subscribe a network with small installed-base as the initial size of the network may affect their expectations on how the network will grow. In contrast with the coordination problem in (a single-layered) platform competition, the coordination problem present in this setting does not involve end-users, but the downstream firms that choose their upstream networks. Furthermore, the key expectation in the coordination problem is the rival firm's choice of upstream network.

${ }^{2}$ See, for example, Rey and Tirole (2007) who consider Cournot competition and secret offers, and show that in the presence of a relatively inefficient supplier, downstream firms end up buying inputs from the efficient upstream firm.

${ }^{3}$ See also Riordan (1998); in an asymmetric market where the dominant downstream firm considers a backward integration vertical integration is anticompetitive, in that it increases both input and output prices.

${ }^{4}$ See also White (2007); when there is incomplete information on the upstream firm's cost, in contrast with a vertically separated structure, vertical integration by a high-cost firm does not involve costly signaling efforts and hence, may be socially beneficial.

${ }^{5}$ See Riordan (2005) for an extensive review of competitive effects of vertical integration.

${ }^{6}$ Norway is an exception. In France the national regulator's attempt to regulate access was rejected by the European Commission.

${ }^{7}$ The setting is not a good fit for those VMNO business models that entail merely resale agreements.

${ }^{8} \mathrm{Katz}$ and Shapiro (1985) is one of the most influential papers in the general literature on compatibility in the presence of network externalities. See also Farrell and Saloner (1986), (1992), Economides and White (1994), and Economides (1996). An overview of this literature is provided by Liebowitz and Margolis (2002), Farrell and Klemperer (2002).

${ }^{9}$ The framework that is provided in this paper is different than "systems competition" where end con- 
sumers make the purchase decisions for each of the complementary component that makes a system. For example, Church and Gandal (2000) look at how vertical mergers and foreclosure in systems markets (hardwaresoftware), affect incentives to produce compatible components to the rival systems, where consumers decide both for their hardware and software purchases, and there are no direct network externalities. See also Economides and Salop (1992), where authors assume full compatibility and analyze vertical integration in network markets.

${ }^{10}$ See Kretschmer (2004) for a review of the PC OS industry.

${ }^{11}$ There are potentially other reasons why the smaller network, Appe/Macintosh, is an integrated network that excludes other computer manufacturers (e.g., control on quality), that my framework does not address. My model also excludes the possibility of one network investing in one-way compatibility (e.g., Paralells Desktop by Mac developed by Apple runs Windows applications). In the absence of those factors, my model would predict an open system (possibly a vertically separated one) where Mac OS would be available to other downstream firms.

${ }^{12}$ The focus of the paper is a local market, and the installed bases of the networks (customers in other markets) are exogenous.

${ }^{13}$ Note that, the lower bound of $\theta$, which is normalized to zero reflects minimum quality of interconnection between the networks that is achieved in the absence of any additional investments in quality that are undertaken by the networks. In some instances (i.e., no prior investments in quality of interconnection), it may correspond to no connectivity.

${ }^{14}$ Market cornering happens, for example, when the downstream firms connect to different upstream networks that charge the same price $w$, and all end-users subscribe to the downstream firm which is connected to the large network.

${ }^{15}$ In a symmetric $2 \times 2$ game risk dominant equilibrium is defined by the profile where both players playing their risk dominant strategy in which they strictly prefer the same action when they predict that their opponent randomizes $\frac{1}{2}-\frac{1}{2}$.

${ }^{16}$ However, when advantage from the installed base, $\varphi \beta$, is very small (when $(n-m) \rightarrow 0$ ), risk dominance may not provide a very good prediction. 
${ }^{17}$ Here, networks make their price offers publicly and simultaneously. These results do not hold when sequential contracting is allowed. In particular, commitment of any of the downstream firms to buy connectivity from, say, the $\mathrm{U}_{A}$, would result with a higher unit price offered by the $\mathrm{U}_{A}$ to the next downstream firm in line.

${ }^{18}$ Otherwise, with vertical integration firms can always replicate the no vertical integration outcome.

${ }^{19}$ When no connectivity occurs, similar to the effect of exclusive dealing in Mathewson and Winter (1987), the large upstream network eliminates the rival upstream firm from the market, and potential competition replaces actual competition (in that the large upstream network can not charge a too high price to the non-integrated downstream firm).

${ }^{20}$ Equilibrium prices for subgames (1)-(4) are computed as in Appendix A.1-4, by replacing relevant equilibrium connectivity prices and quality of interconnection, and a summary table can be found in Appendix A.6.

${ }^{21}$ For example, Malueg and Schwartz (2006) analyze interconnectivity incentives of a large network in a single-layered structure, and assume that small rivals of the large network is perfectly interconnected Note, however, this assumption is hard to impose, in particular, when quality of interconnection is costly. 


\section{Appendix}

\section{A Computation of payoffs for a given $w_{A}, w_{B}$, and $\theta$.}

\section{A.1 Subgame (1) Vertical Separation}

In this section I compute the profits of the downstream firms when there is no vertical integration. There are four possible cases regarding the upstream network choice of the downstream firms.

\section{(1a) $\mathrm{D}_{1}$ and $\mathrm{D}_{2}$ connect to $\mathrm{U}_{A}$}

This case yields perfect connectivity between the downstream firms. The utility to the end user at location $x$ from having access to the end-service is

$$
U= \begin{cases}v-|x-0|+\delta\left(\beta_{A}+q_{1}+\left(1-q_{1}\right)+\theta \beta_{B}\right)-p_{1} & \text { if connects to } \mathrm{D}_{1}, \\ v-|1-x|+\delta\left(\beta_{A}+q_{1}+\left(1-q_{1}\right)+\theta \beta_{B}\right)-p_{2} & \text { if connects to } \mathrm{D}_{2} .\end{cases}
$$

The marginal consumer who is indifferent between connecting to $\mathrm{D}_{1}$ and $\mathrm{D}_{2}$ satisfies $-x-p_{1}=-1+x-p_{2}$. Therefore, $\mathrm{D}_{1}$ has a market share of $x=1 / 2+\left(p_{2}-p_{1}\right) / 2$, and its profit is $\left(p_{1}-w_{A}\right)\left(1 / 2+\left(p_{2}-p_{1}\right) / 2\right)$. Similarly $\mathrm{D}_{2}$ has a market share of $(1-x)=1 / 2-\left(p_{2}-p_{1}\right) / 2$, and its profit is $\left(p_{2}-w_{A}\right)\left(1 / 2-\left(p_{2}-p_{1}\right) / 2\right)$.

The Nash equilibrium of the subgame yields $p_{1}=p_{2}=w_{A}+1$, which implies $\Pi_{A}^{(1 \mathrm{a})}=w_{A}, \Pi_{B}^{(1 \mathrm{a})}=0$, and $\Pi_{1}^{(1 \mathrm{a})}=\Pi_{2}^{(1 \mathrm{a})}=\frac{1}{2}$.

(1b) $D_{1}$ connects to $U_{A}$ and $D_{2}$ connects to $U_{B}$

The utility to the end user at location $x$ from having access to the end-service is

$$
U= \begin{cases}v-|x-0|+\delta\left(\beta_{A}+q_{1}+\theta\left(\beta_{B}+\left(1-q_{1}\right)\right)\right)-p_{1} & \text { if connects to } \mathrm{D}_{1} \\ v-|1-x|+\delta\left(\theta\left(\beta_{A}+q_{1}\right)+\beta_{B}+\left(1-q_{1}\right)\right)-p_{2} & \text { if connects to } \mathrm{D}_{2}\end{cases}
$$


The marginal consumer who is indifferent between connecting to $\mathrm{D}_{1}$ and $\mathrm{D}_{2}$ satisfies

$$
-x+\delta \beta_{A}+\delta x+\delta \theta \beta_{B}+\delta \theta(1-x)-p_{1}=-1+x+\delta \theta \beta_{A}+\delta \theta x+\delta \beta_{B}+\delta(1-x)-p_{2}
$$

$\mathrm{D}_{1}$ has a market share of

$$
x=\frac{1}{2}+\frac{\varphi \beta}{2(1-\varphi)}+\frac{p_{2}-p_{1}}{2(1-\varphi)} .
$$

Profits of $\mathrm{D}_{1}$ and $\mathrm{D}_{2}$ are

$$
\Pi_{1}^{(1 \mathrm{~b})}=\left(p_{1}-w_{A}\right)\left(\frac{1}{2}+\frac{\varphi \beta}{2(1-\varphi)}+\frac{p_{2}-p_{1}}{2(1-\varphi)}\right)
$$

and

$$
\Pi_{2}^{(1 \mathrm{~b})}=\left(p_{2}-w_{B}\right)\left(\frac{1}{2}-\frac{\varphi \beta}{2(1-\varphi)}+\frac{p_{1}-p_{2}}{2(1-\varphi)}\right)
$$

respectively. For all $w \in[\varphi \beta-3(1-\varphi), 3(1-\varphi)+\varphi \beta]$, the Nash equilibrium of the subgame yields $p_{1}=$ $(1-\varphi)+\left(2 w_{A}+w_{B}\right) / 3+\varphi \beta / 3$, and $p_{2}=(1-\varphi)+\left(2 w_{B}+w_{A}\right) / 3-\varphi \beta / 3$, which implies

$$
\Pi_{1}^{(1 \mathrm{~b})}=\frac{(3(1-\varphi)-w+\varphi \beta)^{2}}{18(1-\varphi)}
$$

and

$$
\Pi_{2}^{(1 \mathrm{~b})}=\frac{(3(1-\varphi)+w-\varphi \beta)^{2}}{18(1-\varphi)} .
$$

\section{(1c) $\mathrm{D}_{1}$ connects to $\mathrm{U}_{B}$ and $\mathrm{D}_{2}$ connects to $\mathrm{U}_{A}$}

Similar to $(1 \mathrm{~b})$, for all $w \in[\varphi \beta-3(1-\varphi), 3(1-\varphi)+\varphi \beta]$ profits of $\mathrm{D}_{1}$ and $\mathrm{D}_{2}$, are

$$
\Pi_{1}^{(1 \mathrm{c})}=\frac{(3(1-\varphi)+w-\varphi \beta)^{2}}{18(1-\varphi)}
$$

and

$$
\Pi_{2}^{(1 \mathrm{c})}=\frac{(3(1-\varphi)-w+\varphi \beta)^{2}}{18(1-\varphi)}
$$

respectively. 


\section{(1d) $D_{1}$ and $D_{2}$ connects to $U_{B}$}

This case yields perfect connectivity between the downstream firms. The utility of the end user at location $x$ from having access to the end-service is

$$
U= \begin{cases}v-|x-0|+\delta\left(\beta_{B}+q_{1}+\left(1-q_{1}\right)+\theta \beta_{A}\right)-p_{1} & \text { if connects to } \mathrm{D}_{1} \\ v-|1-x|+\delta\left(\beta_{B}+q_{1}+\left(1-q_{1}\right)+\theta \beta_{A}\right)-p_{2} & \text { if connects to } \mathrm{D}_{2} .\end{cases}
$$

Similar to (1a) we have $p_{1}=p_{2}=w_{A}+1$, which implies $\Pi_{A}^{(1 \mathrm{~d})}=0, \Pi_{B}^{(1 \mathrm{~d})}=w_{B}$, and $\Pi_{1}^{(1 \mathrm{~d})}=\Pi_{2}^{(1 \mathrm{~d})}=\frac{1}{2}$.

\section{A.2 Subgame (2) $\mathrm{U}_{B}$ integrates with $\mathrm{D}_{2}$}

\section{(2a) $D_{1}$ connects to $U_{B}$}

The utility to the end user at location $x$ from having access to the end-service is defined as in equation (A.1d). The Nash equilibrium of the subgame is computed similarly, except that the $\mathrm{U}_{B}$ charges zero price to $\mathrm{D}_{2}$, and charges $w_{B}$ to $\mathrm{D}_{1}$. Equilibrium prices are $p_{2}^{(2 \mathrm{a})}=1+w_{B} / 3$, and $p_{1}^{(2 \mathrm{a})}=1+2 w_{B} / 3$, which implies for all $w_{B} \in[0,3], \Pi_{A}^{(2 \mathrm{a})}=0$ (as $\mathrm{U}_{A}$ sells no connectivity in this market), $\Pi_{B}^{(2 \mathrm{a})}=\left(3-w_{B}\right) w_{B} / 6$, $\Pi_{1}^{(2 \mathrm{a})}=\left(3-w_{B}\right)^{2} / 18, \Pi_{2}^{(2 \mathrm{a})}=\left(3+w_{B}\right)^{2} / 18$. The integrated firm's profit is composed of $\Pi_{2}^{(2 \mathrm{a})}$ and the profit obtained by selling connectivity to $\mathrm{D}_{1}$, hence it obtains

$$
\Pi_{B}^{(2 \mathrm{a})}\left(w_{B}\right)+\Pi_{2}^{(2 \mathrm{a})}\left(w_{B}\right)=\frac{\left(3+w_{B}\right)^{2}}{18}+\frac{\left(3-w_{B}\right)}{6} w_{B}
$$

\section{(2b) $\mathrm{D}_{1}$ exits}

Consider the case in which $\mathrm{U}_{B}$ does not sell connectivity (either charges too high a price, or refuses to supply) to $\mathrm{D}_{1}$, and $\mathrm{D}_{1}$ gains a negative market share if it buys connectivity from $\mathrm{U}_{A}$. In this case, $\mathrm{D}_{1}$ withdraws from the market, and the integrated upstream network becomes a monopolist in the downstream market. Therefore, $\Pi_{1}^{(2 \mathrm{a})}=0, \Pi_{A}^{(2 \mathrm{a})}=0$, and the integrated upstream network obtains monopoly profits denoted with $\Pi_{B}^{(2 \mathrm{a})}+\Pi_{2}^{(2 \mathrm{a})}=\Pi\left(v, \delta, \beta_{B}\right)>0$, where $\Pi\left(v, \delta, \beta_{B}\right)>0$, is increasing in all its arguments. 


\section{(2c) $\mathrm{D}_{1}$ connects to $\mathrm{U}_{A}$}

The utility of the end user at location $x$ from having access to the end-service is defined as in equation (A.1b). The Nash equilibrium of the subgame is computed similarly, except that the $\mathrm{U}_{B}$ charges zero price to $\mathrm{D}_{2}$, and $\mathrm{U}_{A}$ charges $w_{A}$ to $\mathrm{D}_{1}$. Equilibrium prices are $p_{1}^{(2 \mathrm{c})}=\left(3(1-\varphi)+\varphi \beta+2 w_{A}\right) / 3$ and $p_{2}^{(2 \mathrm{c})}=\left(3(1-\varphi)-\varphi \beta+w_{A}\right) / 3$, which implies that for all $w_{A} \in[0,3(1-\varphi)+\varphi \beta]$,

$$
\begin{gathered}
\Pi_{A}^{(2 \mathrm{c})}\left(w_{A}\right)=\left(\frac{3(1-\varphi)+\varphi \beta-w_{A}}{6(1-\varphi)}\right) w_{A}, \\
\Pi_{B}^{(2 \mathrm{c})}=0 \\
\Pi_{1}^{(2 \mathrm{c})}\left(w_{A}\right)=\frac{\left(3(1-\varphi)+\varphi \beta-w_{A}\right)^{2}}{18(1-\varphi)}
\end{gathered}
$$

and

$$
\Pi_{2}^{(2 c)}\left(w_{A}\right)=\frac{\left(3(1-\varphi)-\varphi \beta+w_{A}\right)^{2}}{18(1-\varphi)}
$$

\section{A.3 Subgame (3) $\mathrm{U}_{A}$ integrates with $\mathrm{D}_{1}$}

\section{(3a) $D_{2}$ connects to $U_{B}$}

The utility to the end user at location $x$ from having access to the end-service is defined as in equation (A.1b). The Nash equilibrium of the subgame is computed similarly, except that the $\mathrm{U}_{A}$ charges zero price to $\mathrm{D}_{1}$, and $\mathrm{U}_{B}$ charges $w_{B}$ to $\mathrm{D}_{2}$. Equilibrium prices are $p_{1}^{(3 \mathrm{a})}=\left(3(1-\varphi)+\varphi \beta+w_{B}\right) / 3$ and $p_{2}^{(3 \mathrm{a})}=$ $\left(3(1-\varphi)-\varphi \beta+2 w_{B}\right) / 3$, which implies that for all $w_{B} \in[0,3(1-\varphi)-\varphi \beta]$,

$$
\begin{gathered}
\Pi_{A}^{(3 \mathrm{a})}=0 \\
\Pi_{B}^{(3 \mathrm{a})}\left(w_{B}\right)=\left(\frac{3(1-\varphi)-\varphi \beta-w_{B}}{6(1-\varphi)}\right) w_{B}, \\
\Pi_{1}^{(3 \mathrm{a})}\left(w_{B}\right)=\frac{\left(3(1-\varphi)+\varphi \beta+w_{B}\right)^{2}}{18(1-\varphi)},
\end{gathered}
$$


and

$$
\Pi_{2}^{(3 \mathrm{a})}\left(w_{B}\right)=\frac{\left(3(1-\varphi)-\varphi \beta-w_{B}\right)^{2}}{18(1-\varphi)}
$$

(3b) $D_{2}$ exits

Consider the case in which $\mathrm{U}_{A}$ does not sell connectivity (either charges a too high price, or refuses to supply) to $\mathrm{D}_{2}$, and $\mathrm{D}_{2}$ gains a negative market share if it buys connectivity from $\mathrm{U}_{B}$. In this case, $\mathrm{D}_{2}$ withdraws from the market, and the integrated downstream firm becomes a monopolist in the downstream market.

Therefore, $\Pi_{B}^{(3 \mathrm{~b})}=0$ (as $\mathrm{U}_{A}$ sells no connectivity in this market), $\Pi_{2}^{(3 \mathrm{~b})}=0$, and the integrated upstream network obtains monopoly profits denoted with $\Pi_{1}^{(3 \mathrm{~b})}+\Pi_{A}^{(3 \mathrm{~b})}=\Pi\left(v, \delta, \beta_{A}\right)$, where $\Pi\left(v, \delta, \beta_{A}\right)>0$, and is increasing in all its arguments.

\section{(3c) $\mathbf{D}_{2}$ connects to $U_{A}$}

The utility to the end user at location $x$ from having access to the end-service is as in equation (A.1a). The Nash equilibrium of the subgame is computed similarly, except that the $\mathrm{U}_{A}$ charges zero price to $\mathrm{D}_{1}$, and charges $w_{A}$ to $\mathrm{D}_{2}$. Equilibrium prices are $p_{1}^{(3 \mathrm{c})}=1+w_{A} / 3$, and $p_{2}^{(3 \mathrm{c})}=1+2 w_{A} / 3$, which implies $\Pi_{A}^{(3 \mathrm{c})}\left(w_{A}\right)=\left(3-w_{A}\right) w_{A} / 6, \Pi_{B}^{(3 \mathrm{c})}=0, \Pi_{1}^{(3 \mathrm{c})}\left(w_{A}\right)=\left(3+w_{A}\right)^{2} / 18$, and $\Pi_{2}^{(3 \mathrm{c})}\left(w_{A}\right)=\left(3-w_{A}\right)^{2} / 18$ for all $w_{A} \in[0,3]$ for $w_{A} \leq 3$. The integrated firm's profit is composed of $\Pi_{1}^{(3 \mathrm{c})}$ and the profit obtained by selling connectivity to $\mathrm{D}_{2}$, hence it obtains

$$
\Pi_{A}^{(3 \mathrm{c})}\left(w_{A}\right)+\Pi_{1}^{(3 \mathrm{c})}\left(w_{A}\right)=\frac{\left(3+w_{A}\right)^{2}}{18}+\frac{\left(3-w_{A}\right)}{6} w_{A}
$$

\section{A.4 Subgame (4) Two vertically integrated networks}

The utility to the end user at location $x$ from having access to the end-service is defined as in equation (A.1b). The Nash equilibrium of the subgame is computed similarly, except that the $\mathrm{U}_{A}$ charges zero price to $\mathrm{D}_{1}$, and $\mathrm{U}_{B}$ charges zero price to $\mathrm{D}_{2}$. Equilibrium prices are $p_{1}^{(4)}=(3(1-\varphi)+\varphi \beta) / 3$ and $p_{2}^{(4)}=(3(1-\varphi)-\varphi \beta) / 3$, which implies hat gross profits are $\Pi_{A}^{(4)}=0, \Pi_{B}^{(4)}=0$,

$$
\Pi_{1}^{(4)}=\frac{(3(1-\varphi)+\varphi \beta)^{2}}{18(1-\varphi)}
$$


and

$$
\Pi_{2}^{(4)}=\frac{(3(1-\varphi)-\varphi \beta)^{2}}{18(1-\varphi)}
$$

\section{A.5 Summary of gross payoffs for a given $\theta, w_{A}$ and $w_{B}$}

[Table 2 here]

\section{A.6 Summary of the equilibrium prices for each subgame}

[Table 3 here]

$\left(^{*}\right)$ Prices for $\beta>\widetilde{\beta}$. For $\beta \leq \widetilde{\beta}$, term $\delta$ should be replaced by $\delta(1-\theta)$.

\section{B Proofs of Lemmas and Propositions}

\section{B.1 Proof of Lemma 3 .}

I first show that in subgames (2) and (3), the non-integrated upstream network is willing to provide connectivity to the non-integrated downstream firm. Then, I show that this is also true for the integrated upstream network.

In subgame (2) we have $\Pi_{A}^{(2 \mathrm{c})}>\Pi_{A}^{(2 \mathrm{~b})}=0$ for $w_{A} \in(0,3(1-\varphi)+\varphi \beta)$ and in subgame (3) we have $\Pi_{B}^{(3 \mathrm{a})}>\Pi_{B}^{(3 \mathrm{~b})}=0$ for $w_{B} \in(0,3(1-\varphi)-\varphi \beta)$, which implies that given the integrated upstream network refuses to deal with the non-integrated downstream firm, the non-integrated upstream network is strictly better off by selling connectivity to the non-integrated downstream firm.

I proceed by showing that in subgame (2), the integrated upstream network, $\mathrm{U}_{B}$, strictly prefers selling connectivity to the non-integrated downstream firm, i.e., if $\Pi_{B}^{(2 \mathrm{a})}+\Pi_{2}^{(2 \mathrm{a})}>\Pi_{B}^{(2 \mathrm{c})}+\Pi_{2}^{(2 \mathrm{c})}$. Under imperfect connectivity $(\varphi>0)$, for a given $w_{B} \in[0,3)$ and a given $w_{A} \in[0,3(1-\varphi)+\varphi \beta)$ (so that $\mathrm{D}_{1}$ obtains a positive market share when it buys connectivity from any of the upstream networks) $\mathrm{D}_{1}$ buys connectivity from $\mathrm{U}_{A}$ if $\Pi_{1}^{(2 \mathrm{c})}\left(w_{A}\right) \geq \Pi_{1}^{(2 \mathrm{a})}\left(w_{B}\right)$, that is, if

$$
w_{A} \leq 3(1-\varphi)+\varphi \beta-\left(3-w_{B}\right) \sqrt{(1-\varphi)},
$$


and buys from $\mathrm{U}_{B}$ if otherwise. When $\mathrm{D}_{1}$ buys connectivity from $\mathrm{U}_{A}$, the integrated upstream network obtains

$$
\Pi_{B}^{(2 \mathrm{c})}+\Pi_{2}^{(2 \mathrm{c})}=0+\frac{\left(3(1-\varphi)-\varphi \beta+w_{A}\right)^{2}}{18(1-\varphi)}
$$

which is increasing with $w_{A}$. Given the constraint defined with inequality (B.1), the maximum level of profits the integrated firm can obtain under $(2 \mathrm{c})$ is found by replacing $w_{A}=3(1-\varphi)+\varphi \beta-\left(3-w_{B}\right) \sqrt{(1-\varphi)}$ in $\Pi_{B}^{(2 \mathrm{c})}+\Pi_{2}^{(2 \mathrm{c})}$, and is

$$
\frac{\left(6(1-\varphi)-\sqrt{(1-\varphi)}\left(3-w_{B}\right)\right)^{2}}{18(1-\varphi)}
$$

When $w_{A}$ is sufficiently high (inequality (B.1) holds in the opposite direction) so that the integrated upstream network sells connectivity to $\mathrm{D}_{1}$, and it obtains

$$
\Pi_{B}^{(2 \mathrm{a})}+\Pi_{2}^{(2 \mathrm{a})}=\frac{\left(3+w_{B}\right)^{2}}{18}+\frac{\left(3-w_{B}\right)^{2}}{6} w_{B}
$$

One can verify that for all $w_{B} \in(0,3)$, we have

$$
\frac{\left(3+w_{B}\right)^{2}}{18}+\frac{\left(3-w_{B}\right)^{2}}{6} w_{B}>\frac{\left(6(1-\varphi)-\sqrt{(1-\varphi)}\left(3-w_{B}\right)\right)^{2}}{18(1-\varphi)}
$$

since it simplifies to

$$
2 \varphi-\frac{1}{6}\left(3-w_{B}\right)\left(w_{B}^{2}-3 w_{B}+4\right)+\frac{2}{3} \sqrt{(1-\varphi)}\left(3-w_{B}\right)>0
$$

which this is true for $\varphi \in(0,1)$ and $w_{B} \in(0,3)$. This concludes that the integrated small upstream network prefers to sell connectivity to the non-integrated downstream firm.

Finally, I show that in subgame (3), the integrated upstream network, $\mathrm{U}_{A}$, is better off by selling connectivity to $D_{2}$ at a price such that $D_{2}$ buys connectivity from it. $D_{2}$ buys connectivity from $U_{A}$ if $\Pi_{2}^{(3 \mathrm{a})}\left(w_{B}\right) \leq \Pi_{2}^{(3 \mathrm{c})}\left(w_{A}\right)$, i.e., if

$$
w_{A} \leqslant 3-\frac{\left(3(1-\varphi)-\varphi \beta-w_{B}\right)}{\sqrt{1-\varphi}}
$$


and if (ii) it obtains non-negative profits by doing so, i.e., if $w_{A} \in[0,3)$. For all $w_{B} \in(0,3(1-\varphi)-\varphi \beta)$, we have the second term of the right-hand side of the inequality (B.2) positive, and hence, (i) implies (ii). It is easy to verify that $\mathrm{U}_{A}$ 's profits under $(3 \mathrm{c})$ are increasing with $w_{A}$ for all $w_{A} \in(0,3)$ (since the unconstrained maximization problem yields $\left.w_{A}^{*}=3.75\right)$. This, in turn, implies that optimal price is the highest price that satisfies inequality (B.2). Given $w_{B} \in(0,3(1-\varphi)-\varphi \beta)$, when $\mathrm{U}_{A}$ charges the optimal price, we have $\Pi_{A}^{(3 \mathrm{c})}+\Pi_{1}^{(3 \mathrm{c})}>\Pi_{A}^{(3 \mathrm{a})}+\Pi_{1}^{(3 \mathrm{a})}$ for all $\beta \in(0,(1-\delta) / \delta]$, which concludes that in subgame $(3) \mathrm{U}_{A}$ is better off by selling connectivity to $\mathrm{D}_{2}$ than by refusing to deal.

B.2 Proof of Lemma 4. (i) It suffices to compare $\partial\left(\Pi_{B}^{(4)}+\Pi_{2}^{(4)}\right) / \partial \theta$ and $\partial\left(\Pi_{A}^{(4)}+\Pi_{1}^{(4)}\right) / \partial \theta$, since the cost function for quality of interconnection is same for both firms. We have $\partial\left(\Pi_{B}^{(4)}+\Pi_{2}^{(4)}\right) / \partial \theta>$ $\partial\left(\Pi_{A}^{(4)}+\Pi_{1}^{(4)}\right) / \partial \theta$ if $12 \beta(1-\delta(1-\theta))^{2}>0$, which is true for all $\beta, \delta$, and $\theta$. It is also straightforward to show that $\Pi_{A}^{(4)}+\Pi_{1}^{(4)}>\Pi_{B}^{(4)}+\Pi_{2}^{(4)}$, for all $\theta$. Replacing for gross profits, and simplifying yields $(1-\theta)(1-\delta(1-\theta))>0$, which is true for all $\theta$.

(ii) The sign of $\partial\left(\partial\left(\Pi_{A}^{(4)}+\Pi_{1}^{(4)}\right) / \partial \theta\right) / \partial \beta$ is the same as the sign of

$$
3 \delta(1-\theta)(2+\theta \delta-\delta)-\delta \beta(1-\theta)(2+\theta \delta-\delta)-3
$$

which is decreasing with $\beta$ and is negative for $\beta=0$ for all $\theta<1$. Therefore, we have $\partial\left(\partial\left(\Pi_{A}^{(4)}+\Pi_{1}^{(4)}\right) / \partial \theta\right) / \partial \beta<$ 0 for all $\beta$, and $\theta<1$. Since cost of connectivity is independent of $\beta$, this concludes that the optimal quality of connection is decreasing with $\beta$.

(iii) Connectivity is determined by $U_{A}$ 's preferences. We have $\partial\left(\Pi_{A}^{(4)}-\theta^{2} / 2\right) / \partial \theta$ decreasing with beta, and

$$
\left.\frac{\partial\left(\Pi_{A}-\theta^{2} / 2\right)}{\partial \theta}\right|_{\theta=0}=0
$$

for $\beta=3(1-\delta) /(2-\delta)$. Therefore, the optimal quality of connectivity is minimum for all

$$
\beta>\frac{3(1-\delta)}{2-\delta} \equiv \widetilde{\beta}
$$

and is positive for all $\beta \leq \widetilde{\beta}$. 
Equilibrium Payoffs are

$$
\Pi_{A}^{(4)}+\Pi_{1}^{(4)}=\frac{(3(1-\delta)+\delta \beta)^{2}}{18(1-\delta)}
$$

and

$$
\Pi_{B}^{(4)}+\Pi_{2}^{(4)}=\frac{(3(1-\delta)-\delta \beta)^{2}}{18(1-\delta)}
$$

for For $\beta>\widetilde{\beta}$, and

$$
\Pi_{A}^{(4)}+\Pi_{1}^{(4)}=\frac{(3(1-\delta(1-\theta))+\delta(1-\theta) \beta)^{2}}{18(1-\delta(1-\theta))}-\frac{\theta^{2}}{2}
$$

and

$$
\Pi_{B}^{(4)}+\Pi_{2}^{(4)}=\frac{(3(1-\delta(1-\theta))-\delta(1-\theta) \beta)^{2}}{18(1-\delta(1-\theta))}-\frac{\theta^{2}}{2}
$$

For $\beta \leq \widetilde{\beta}$.

B.3 Proof of Lemma 5. It is straightforward to conclude that price competition ends with $w_{A}^{(3)}=$ $3-(3(1-\varphi)-\varphi \beta) / \sqrt{1-\varphi}$, and $w_{B}^{(3)}=0$, since $w_{A}^{(3)}$ is the optimal price for $\mathrm{U}_{A}$ and is strictly positive for all $\varphi \in(0,1]$ (i.e., for all $\theta \in[0,1)$ ). Finally, $\mathrm{D}_{2}$ buys connectivity from $\mathrm{U}_{A}$ since $w_{A}^{(3)}$ and $w_{B}^{(3)}$ satisfy the constraint defined in inequality (B.2) (see Proof of Lemma 3) with equality.

B.4 Proof of Lemma 6. Gross profits of the large network is

$$
\frac{\left(3+w_{A}\right)^{2}}{18}+\frac{\left(3-w_{A}\right)}{6} w_{A}
$$

which is increasing for all $w_{A}>3.75$. Note that for any $w_{A} \geq 3$, the non-integrated firm gets non positive profits if it buys connectivity from the large network. We have

$$
\frac{\partial w_{A}^{(3)}}{\partial \varphi}=\frac{(2 \beta-3 \varphi-\beta \varphi+3)}{2(\sqrt{1-\varphi})(1-\varphi)}>0
$$

Therefore re, $w_{A}^{(3)}$ increasing with $\varphi$, and hence decreasing with $\theta$, which implies that the gross profits of the large network is decreasing with $\theta$. Since quality of interconnection is costly, this also concludes that the net profits of the large network is decreasing with $\theta$. 
B.5 Proof of Lemma 7. Lemma ?? shows that in this subgame the upstream networks compete for providing access to the non-integrated downstream firm. Problem of $\mathrm{U}_{B}$ is defined as follows.

$$
\max \Pi_{B}^{(2 \mathrm{a})}+\Pi_{2}^{(2 \mathrm{a})}=\max \left(\frac{\left(3+w_{B}\right)^{2}}{18}+\frac{\left(3-w_{B}\right)}{6} w_{B}\right)
$$

subject to $w_{B} \leq 3$ and $\Pi_{1}^{(2 \mathrm{a})}\left(w_{B}\right) \geq \Pi_{1}^{(2 \mathrm{c})}\left(w_{A}\right)$. The first constraint ensures a non-negative market share for $\mathrm{D}_{1}$ when it buys access from $\mathrm{U}_{B}$, and the second constraint ensures that $\mathrm{D}_{1}$ prefers buying access from $\mathrm{U}_{B}$ instead of $\mathrm{U}_{A}$. The second constraint can be rewritten as

$$
\frac{\left(3-w_{B}\right)^{2}}{18} \geq \frac{\left(3(1-\varphi)+\varphi \beta-w_{A}\right)^{2}}{18(1-\varphi)}
$$

for all $w_{B} \in[0,3]$ and $w_{A} \in[0,3(1-\varphi)+\varphi \beta]$, and can be simplified to

$$
w_{B} \leq 3-\frac{3(1-\varphi)+\varphi \beta-w_{A}}{\sqrt{(1-\varphi)}} \equiv \bar{w}_{B}
$$

First assume that the installed-base difference is sufficiently small so that price competition between the upstream networks derives prices to $w_{A}=0$ and $w_{B} \geq 0$ (upstream firms are competing in prices, and hence, when either of the upstream firm is selling connectivity to $D_{1}$, the other upstream firm must be charging a zero price at the equilibrium, so there are no unilateral incentives to deviate), and $\mathrm{U}_{B}$ sells access to $\mathrm{D}_{1}$ (i.e., industry configuration is $(2 \mathrm{a})$ ). The second-order condition is satisfied as $-2 / 9<0$, and the unconstrained optimal price defined by the first-order condition is 3.75. Since the unconstrained optimal price is higher than both constraints, and since we have $\bar{w}_{B}<3$ for $w_{A}=0, w_{B}^{(2 \mathrm{a})}$ is defined by the highest price that satisfies $w_{B} \leq \bar{w}_{B}$; i.e.,

$$
w_{B}^{(2 a)}=3-\frac{3(1-\varphi)+\varphi \beta}{\sqrt{(1-\varphi)}}
$$

When (2a) is the equilibrium industry configuration, $\mathrm{U}_{A}$ can not attract $\mathrm{D}_{1}$ with a non-negative price, and (2a) is the equilibrium industry configuration if $w_{B}^{(2 \mathrm{a})}$ is non-negative, that is, if

$$
\beta \leq \frac{3 \sqrt{(1-\varphi)}-3(1-\varphi)}{\varphi} .
$$


Second, assume that installed-base difference is sufficiently large so that $\mathrm{U}_{B}$ can not attract $\mathrm{D}_{1}$ with a nonnegative price. Then price competition derives $w_{B}=0$ and $w_{A} \geq 0$, and $\mathrm{U}_{A}$ sells access to $\mathrm{D}_{1}$ (the industry configuration is $(2 c))$. Problem of $\mathrm{U}_{A}$ is defined as follows.

$$
\max \Pi_{A}^{(2 \mathrm{c})}=\max \left(\frac{3(1-\varphi)+\varphi \beta-w_{A}}{6(1-\varphi)}\right) w_{A},
$$

subject to $w_{A} \leq 3(1-\varphi)+\varphi \beta$ and $\Pi_{1}^{(2 \mathrm{c})}\left(w_{A}\right)>\Pi_{1}^{(2 \mathrm{a})}\left(w_{B}\right)$. The first constraint ensures a non-negative market share for $\mathrm{D}_{1}$ when it buys access from $\mathrm{U}_{A}$, and the second constraint ensures that $\mathrm{D}_{1}$ prefers buying access from $\mathrm{U}_{A}$ instead of $\mathrm{U}_{B}$. The second constraint can be rewritten as

$$
\frac{\left(3(1-\varphi)+\varphi \beta-w_{A}\right)^{2}}{18(1-\varphi)}>\frac{1}{2}
$$

for $w_{B}=0$, and can be simplified to

$$
w_{A} \leq 3(1-\varphi)+\varphi \beta-3 \sqrt{(1-\varphi)} \equiv \bar{w}_{A}
$$

First-order condition to $\mathrm{U}_{A}$ 's problem is

$$
\frac{\partial \Pi_{A}^{(2 c)}}{\partial w_{A}}=\frac{w_{A}}{6 \varphi-6}+\frac{1}{6 \varphi-6}\left(3 \varphi-\beta \varphi+w_{A}-3\right)=0
$$

and the second-order condition is satisfied as $1 / 3 \varphi-3<0$. Therefore, the unconstrained optimum yields

$$
\widetilde{w}_{A}=\frac{3(1-\varphi)+\beta \varphi}{2}
$$

Since we have $\widetilde{w}_{A} \in[0,3(1-\varphi)+\varphi \beta]$, it remains to verify whether $\widehat{w}_{A} \leq \bar{w}_{A}$, that is, if

$$
\frac{(3-3 \varphi+\beta \varphi)}{2} \leq 3(1-\varphi)+\varphi \beta-3 \sqrt{(1-\varphi)}
$$


which can be rewritten as

$$
\beta>\frac{6 \sqrt{1-\varphi}-3(1-\varphi)}{\varphi}
$$

Below, I show that this inequality does not hold for any $\beta<(1-\delta) / \delta$. Multiplying and diving the right hand side of this inequality with $(1-\theta)$ yields $\beta<(1-\varphi-\theta) / \varphi$. It remains to show that

$$
\frac{6 \sqrt{1-\varphi}-3(1-\varphi)}{\varphi}>\frac{1-\varphi-\theta}{\varphi}
$$

which can be rewritten as

$$
6 \sqrt{1-\delta(1-\theta)}-4(1-\delta(1-\theta))-\theta>0
$$

and which is always true for $\theta \in[0,1]$ and $\delta \in[0,1]$. Therefore, the constraint is binding at the optimum, and the optimal access price under this industry configuration, $w_{A}^{(2 \mathrm{c})}$ is defined by the maximum price that satisfies $w_{A} \leq \bar{w}_{A}$, i.e.,

$$
w_{A}^{(2 \mathrm{c})}=3(1-\varphi)+\varphi \beta-3 \sqrt{(1-\varphi)}
$$

(2c) is the equilibrium industry configuration if $w_{A}^{(2 c)} \geq 0$, that is if

$$
\begin{aligned}
& 3(1-\varphi)+\varphi \beta-3 \sqrt{(1-\varphi)} \geq 0 \\
& \beta>\frac{3 \sqrt{(1-\varphi)}-3(1-\varphi)}{\varphi}=\widehat{\beta}
\end{aligned}
$$

To summarize; given that $\mathrm{U}_{B}$ integrates with $\mathrm{D}_{2}$, if $\beta \leq \widehat{\beta}$, and the equilibrium industry configuration is characterized with (2a), where $\mathrm{D}_{1}$ buys connectivity from $\mathrm{U}_{B}$. The equilibrium connectivity prices and profits are $w_{B}^{(2 \mathrm{a})}=3-(3(1-\varphi)+\varphi \beta) / \sqrt{(1-\varphi)}, w_{A}^{(2 \mathrm{a})}=0, \Pi_{A}^{(2 \mathrm{a})}=0$,

$$
\begin{gathered}
\Pi_{1}^{(2 \mathrm{a})}=\frac{(3(1-\varphi)+\beta \varphi)^{2}}{18(1-\varphi)} \\
\Pi_{2}^{(2 \mathrm{a})}=\frac{(6 \sqrt{(1-\varphi)}-3(1-\varphi)-\varphi \beta)^{2}}{18(1-\varphi)}
\end{gathered}
$$




$$
\Pi_{B}^{(2 \mathrm{a})}=\frac{(3 \varphi-\beta \varphi+3 \sqrt{1-\varphi}-3)(\beta \varphi-3 \varphi+3)}{6(1-\varphi)}
$$

If $\beta>\widehat{\beta}$, the equilibrium industry configuration is characterized with (2c), where $\mathrm{D}_{1}$ buys connectivity from $\mathrm{U}_{A}$, and the equilibrium connectivity prices and profits are $w_{A}^{(2 \mathrm{c})}=3(1-\varphi)+\varphi \beta-3 \sqrt{(1-\varphi)}, w_{B}^{(2 \mathrm{c})}=0$, $\Pi_{1}^{(2 \mathrm{c})}=1 / 2, \Pi_{B}^{(2 \mathrm{c})}=0$

$$
\begin{gathered}
\Pi_{A}^{(2 \mathrm{c})}=\frac{(3-3 \varphi+\beta \varphi-3 \sqrt{1-\varphi})(\sqrt{1-\varphi})}{2(1-\varphi)} \\
\Pi_{2}^{(2 \mathrm{c})}=\frac{(2-2 \varphi-\sqrt{1-\varphi})^{2}}{2(1-\varphi)}
\end{gathered}
$$

B.6 Proof of Lemma 8. The proof is straightforward for $\beta \leq \widehat{\beta}$, since at this range we have $\Pi_{A}^{(2 \mathrm{c})}=0$, and hence $\mathrm{U}_{A}$ has no incentives to invest in quality of connection. For $\beta>\widehat{\beta}$ we have net profits (as well as gross profits) of $\mathrm{U}_{A}$ decreasing with $\theta$. As we have

$$
\frac{\partial^{2}\left(\Pi_{A}^{(2 \mathrm{c})}-\theta^{2} / 2\right)}{\partial \theta \partial \beta}=-\frac{(\theta \delta-\delta+2) \delta}{4(\sqrt{\theta \delta-\delta+1})(\theta \delta-\delta+1)}<0
$$

and

$$
\left.\frac{\partial\left(\Pi_{A}^{(2 \mathrm{c})}-\theta^{2} / 2\right)}{\partial \theta}\right|_{\beta=\widehat{\beta}}=\frac{\left(3 \delta-4 \theta+\theta \delta+4 \theta^{2}-8 \theta^{2} \delta+4 \theta^{3} \delta+6 \sqrt{\theta \delta-\delta+1}-6\right)}{4(\theta \delta-\delta+1)(1-\theta)}<0,
$$

for all $\delta>0$, which implies that

$$
\frac{\partial\left(\Pi_{A}^{(2 c)}-\theta^{2} / 2\right)}{\partial \theta}<0
$$

for all $\beta$ and $\delta>0$. This argument applies also to gross profits, since the cost of connectivity is independent of $\beta$.

B.7 Proof of Proposition 3. I begin with studying best response of $\mathrm{U}_{B}$. Given that $\mathrm{U}_{A}$ integrates, the industry configuration is (4) if $\mathrm{U}_{B}$ integrates, and it is (3) if it does not. Therefore, a counter-merger occurs if

$$
\Pi_{B}^{(4)}+\Pi_{2}^{(4)} \geq \Pi_{B}^{(3)}+\Pi_{2}^{(3)}
$$


For all $\beta>\widetilde{\beta}$, we have $\theta=0$, and (B.3) holds with equality. For all $\beta \leq \widetilde{\beta}$ we have $\theta \in(0, \delta / 2]$, and $\theta$ is decreasing with $\beta$. Since (B.3) holds with equality for $\theta=0$, for any optimal quality that is positive, we have (B.3) holds with strict inequality. Therefore, whenever $\mathrm{U}_{A}$ integrates, $\mathrm{U}_{B}$ responds with counter-merger, and the payoffs are as determined in Subgame (4). Given that $\mathrm{U}_{A}$ does not integrate, the industry configuration is (2) if $\mathrm{U}_{B}$ integrates, and it is (1) if it does not. Therefore, $\mathrm{U}_{B}$ integrates with $\mathrm{D}_{1}$ if

$$
\Pi_{B}^{(2)}+\Pi_{2}^{(2)} \geq \Pi_{B}^{(1)}+\Pi_{2}^{(1)}
$$

Equilibrium payoffs in (2) depends on the size of the installed base difference. For $\beta \leq \widehat{\beta}$ inequality (B.4) can be rewritten as

$$
-\frac{\left(12 \beta \delta+18 \delta^{2}-12 \beta \delta^{2}+2 \beta^{2} \delta^{2}+\sqrt{1-\delta}(9-9 \delta+3 \beta \delta)-18\right)}{18(1-\delta)} \geq \frac{1}{2}
$$

which is simplified to

$$
18-18 \delta^{2}-2 \delta \beta(\beta \delta-6 \delta+6)-\sqrt{1-\delta}(9-9 \delta+3 \beta \delta) \geq 0
$$

holds for all $\beta \leq \widehat{\beta}$ (and hence, $\mathrm{U}_{B}$ integrates). For $\beta>\widehat{\beta}$ inequality (B.4) can be rewritten as

$$
\frac{(2-2 \delta-\sqrt{1-\delta})^{2}}{2(1-\delta)} \geq \frac{1}{2}
$$

which is simplified to $1-\delta \geq 1$, does not hold for any $\delta>0$ (and hence, $\mathrm{U}_{B}$ does not integrate).

Going backwards, $\mathrm{U}_{A}$ decides for integration. If $\mathrm{U}_{A}$ integrates, $\mathrm{U}_{B}$ responds with counter-merger, and the equilibrium is characterized with (4), which yields

$$
\Pi_{A}^{(4)}+\Pi_{1}^{(4)}=\frac{(3(1-\delta(1-\theta))+\delta(1-\theta) \beta)^{2}}{18(1-\delta(1-\theta))}-\frac{\theta^{2}}{2} .
$$

If $\mathrm{U}_{A}$ does not integrate, and if $\beta \leq \widehat{\beta} \mathrm{U}_{B}$ integrates with $\mathrm{D}_{2}$ (industry configuration (2a)), $\mathrm{U}_{A}$ and $\mathrm{D}_{1}$ 
obtain

$$
0+\frac{(3(1-\delta)+\beta \delta)^{2}}{18(1-\delta)}
$$

Therefore, if $\beta \leq \widetilde{\beta} \mathrm{U}_{A}$ integrates if

$$
\frac{(3(1-\delta(1-\theta))+\delta(1-\theta) \beta)^{2}}{18(1-\delta(1-\theta))}-\frac{\theta^{2}}{2} \geq 0+\frac{(3(1-\delta)+\beta \delta)^{2}}{18(1-\delta)}
$$

which holds with strict inequality for $\beta \leq \widetilde{\beta}$ and with equality for $\beta \in(\widetilde{\beta}, \widehat{\beta}]$.

Note that $\widetilde{\beta} \leq \widehat{\beta}$ as

$$
\frac{3(1-\delta)}{2-\delta} \leq \frac{3 \sqrt{(1-\delta)}-3(1-\delta)}{\delta}
$$

which be simplified to

$$
2(1-\delta)-(\sqrt{1-\delta})(2-\delta) \leq 0
$$

holds with strict inequality for all $\delta>0$.

If $\beta>\widehat{\beta} \mathrm{U}_{B}$ does not integrate with $\mathrm{D}_{1}$ (industry configuration (1)), and $\mathrm{U}_{A}$ and $\mathrm{D}_{1}$ obtain $\delta \beta+1 / 2$. Since $\widetilde{\beta} \leq \widehat{\beta}$, for all $\beta>\widehat{\beta}$ we have $\theta=0$, and hence, $\mathrm{U}_{A}$ integrates if

$$
\frac{(3(1-\delta)+\delta \beta)^{2}}{18(1-\delta)} \leq \delta \beta+\frac{1}{2}
$$

which can be simplified to

$$
\beta^{2} \delta-9(1-\delta)-12 \beta(1-\delta) \geq 0
$$

does not hold for any $\beta<(1-\delta) / \delta$.

B.8 Proof of Proposition 4. I begin with studying best response of $\mathrm{U}_{A}$. Given that $\mathrm{U}_{B}$ integrates, the industry configuration is (4) if $\mathrm{U}_{A}$ integrates, and it is (2) if it does not. If $\beta \leq \widehat{\beta}$ the sum of equilibrium payoffs of $\mathrm{U}_{A}$ and $\mathrm{D}_{1}$ in (2) are defined as in (2a):

$$
0+\frac{(3(1-\delta)+\beta \delta)^{2}}{18(1-\delta)}
$$


Therefore, $\mathrm{U}_{A}$ integrates if

$$
\frac{(3(1-\delta(1-\theta))+\delta(1-\theta) \beta)^{2}}{18(1-\delta(1-\theta))}-\frac{\theta^{2}}{2} \geq \frac{(3(1-\delta)+\beta \delta)^{2}}{18(1-\delta)}
$$

For $\beta \in(\widetilde{\beta}, \widehat{\beta}]$, quality of interconnection is connectivity is zero, and hence, (B.5) holds with equality. For $\beta<\widetilde{\beta}$, optimal quality of interconnection is positive, and hence, (B.5) holds with strict inequality. This concludes that if $\beta \leq \widehat{\beta}$, best response of $\mathrm{U}_{A}$ to a merger between $\mathrm{U}_{B}$ and $\mathrm{D}_{2}$ is to engage in counter-merger. If $\beta>\widehat{\beta}$ the sum of equilibrium payoffs of $\mathrm{U}_{A}$ and $\mathrm{D}_{1}$ in (2) are defined as in (2c), and is

$$
\frac{(3-3 \delta+\beta \delta-3 \sqrt{1-\delta})(\sqrt{1-\delta})}{2(1-\delta)}+\frac{1}{2}
$$

For all $\beta>\widehat{\beta}$ equilibrium quality of interconnection is zero in (4). Therefore, $\mathrm{U}_{A}$ integrates if

$$
\frac{(3(1-\delta)+\delta \beta)^{2}}{9(1-\delta)} \geq \frac{(3-3 \delta+\beta \delta-3 \sqrt{1-\delta})(\sqrt{1-\delta})}{2(1-\delta)}+\frac{1}{2}
$$

which can be simplified to

$$
(3(1-\delta)+\delta \beta)^{2}-9(\sqrt{1-\delta})(3(1-\delta)+\delta \beta-3 \sqrt{1-\delta})-9(1-\delta) \geq 0
$$

which is not true for any $\beta>\widehat{\beta}$. To see this, let the left hand side of this inequality denoted by $\phi(\beta, \delta)$. We have $\phi(\widehat{\beta}, \delta)=0$, and

$$
\frac{\partial \phi(\beta, \delta)}{\partial \beta}=\delta(2 \beta \delta-6 \delta-9 \sqrt{1-\delta}+6)<0
$$

for all $\beta<(1-\delta) / \delta$. Therefore $\phi(\beta, \delta)<0$ for all $\beta>\widehat{\beta}$. This concludes that if $\beta>\widehat{\beta}$, best response of $\mathrm{U}_{A}$ to a merger between $\mathrm{U}_{B}$ and $\mathrm{D}_{2}$ is not to integrate with $\mathrm{D}_{1}$.

Given that $\mathrm{U}_{B}$ does not integrate, the industry configuration is (3) if $\mathrm{U}_{A}$ integrates, and it is (1) if it does not. Therefore, $\mathrm{U}_{A}$ integrates if

$$
\frac{2 \delta\left(6 \beta-\delta \beta^{2}-6 \delta \beta-9 \delta\right)+18-3 \sqrt{(1-\delta)}(3-3 \delta-\delta \beta)}{18(1-\delta)} \geq \delta \beta+\frac{1}{2}
$$


which simplifies to

$$
\beta \leq \frac{3(2 \delta-2+\sqrt{1-\delta}+\sqrt{(1-\delta)((12 \delta+13)-12(\sqrt{1-\delta}))})}{4 \delta} \equiv \bar{\beta}
$$

For all $\beta>\bar{\beta} \mathrm{U}_{A}$ does not integrate.

Going backwards, $\mathrm{U}_{B}$ decides for integration. If $\mathrm{U}_{B}$ integrates, $\mathrm{U}_{A}$ responds by integrating if $\beta \leq \widehat{\beta}$, and by not integrating, otherwise. Therefore if $\mathrm{U}_{B}$ integrates, for all $\beta \leq \widehat{\beta}$, the equilibrium is characterized by (4) and for all $\beta>\widehat{\beta}$ it is characterized by (2). If $\mathrm{U}_{B}$ does not integrate, it knows that $\mathrm{U}_{A}$ will respond by integrating if $\beta<\bar{\beta}$ (and hence the equilibrium is characterized by (3)), and by not integrating otherwise (and hence the equilibrium is characterized by (1)). One can show that we have $\bar{\beta}>\widehat{\beta}$ for all $\delta \in(0,1)$. If $\beta \leq \widehat{\beta}, \mathrm{U}_{B}$ integrates as

$$
\frac{(3(1-\delta(1-\theta))-\delta(1-\theta) \beta)^{2}}{18(1-\delta(1-\theta))}-\frac{\theta^{2}}{2} \geq 0+\frac{(3(1-\delta)-\delta \beta)^{2}}{18(1-\delta)}
$$

holds with strictly inequality for all $\beta \in[0, \widetilde{\beta}]$ and with equality for all $\beta \in(\widetilde{\beta}, \widehat{\beta}]$. If $\beta \in(\widehat{\beta}, \bar{\beta}), \mathrm{U}_{B}$ integrates as

$$
0+\frac{(2-2 \delta-\sqrt{1-\delta})^{2}}{2(1-\delta)} \geq \frac{(3(1-\delta)-\delta \beta)^{2}}{18(1-\delta)}
$$

can be simplified to $(3(1-\delta)-\delta \beta)-3(2-2 \delta-\sqrt{1-\delta}) \leq 0$, which holds for all $\beta>\widehat{\beta}$. If $\beta>\bar{\beta}, \mathrm{U}_{B}$ does not integrate as

$$
0+\frac{(2-2 \delta-\sqrt{1-\delta})^{2}}{2(1-\delta)}<\frac{1}{2}
$$

which can be simplified to $1-\delta<\sqrt{1-\delta}$, is true for all $\delta \in(0,1)$. 